\title{
1 Role of Nrp1 in controlling cortical interhemispheric circuits
}

2 Martín-Fernández, $\mathrm{F}^{1}$., Briz, C. G. ${ }^{1}$, Nieto, ${ }^{1}{ }^{1}$

$3{ }^{1}$ Department of Cellular and Molecular Biology, Centro Nacional de Biotecnología,

4 Consejo Superior de Investigaciones Científicas (CNB-CSIC), Campus de Cantoblanco,

5 Darwin 3, 28049 Madrid, Spain.

6 *Correspondence to: mnlopez@cnb.csic.es

\section{Abstract}

8 Callosal projections establish topographically organized maps between cortical areas.

9 Neuropilin-1 (Nrp1) cortical gradient induces an early segregation of developing callosal

10 axons. We investigated later roles of Nrp1 on the development of callosal projections

11 from layer (L) 2/3 of the primary (S1) and secondary (S2) somatosensory (SS) areas,

12 which express higher and lower levels of Nrp1, respectively. We used in utero

13 electroporation to knock down or overexpress Nrp1 combined with retrograde tracers, to

14 map connections at postnatal day 16 and 30. High levels of Nrp1 blocked contralateral

15 S2 innervation while promoted the late postnatal growth of homotopic S1L2/3 and

16 heterotopic S2L2/3 branches into S1. Conversely, knocking down Nrp1 increased the

17 growth of heterotopic S1L2/3 projections into S2, and the overall refinement of S2L2/3

18 branches, thereby diminishing the number of P30 S2L2/3 callosally projecting neurons.

19 Thus, the Nrp1 gradient determines homotopic SSL2/3 callosal connectivity by regulating

20 late postnatal branching and refinement in a topographic manner. 


\section{Introduction}

The cerebral cortex is responsible for the execution of higher cognitive functions (Hill and Walsh, 2005). During evolution, the cortex had increased in size and complexity permitting eutherian brains to acquire the corpus callosum (CC). The $\mathrm{CC}$ is a tridimensional structure of myelinated interhemispheric axons that mediates the higher processing of information by establishing a topographically and hierarchically organized communication. It interconnects neurons located in equivalent areas of the hemispheres (homotopic callosal connections), as well as neurons of different modalities and orders (heterotopic connections) (Wise and Jones, 1976; Miller and Vogt, 1984; Rakic, 1988; Fenlon et al., 2017; De León Reyes et al., 2020).

For the correct processing of information, developmental mechanisms must ensure the precise definition of two aspects of the organization of adult CC circuits: firstly, the number of callosally projecting neurons (CPNs) in each cortical area and layer, and secondly, the topographical arrangement of their contralateral axons. Both of these aspects are the result of developmental selection processes including refinement (Aboitiz and Montiel, 2003; Fame et al., 2011; Fenlon and Richards, 2015). Not all cortical areas contain the same number of CPNs. Their precise proportion defines the different functional cortical areas and regions. Associative areas, for instance, contain more CPNs than primary regions. The layer (L) distribution of CPNs also varies within areas, although in general, CPNs are more abundant in L2/3 and L5 of the adult cortex, there are some in L6 and very few in L4. The selection of the axonal targets of these CPNs is also highly specific. Callosal axons branch and synapse in topographically reproducible locations in the contralateral hemisphere. As a rule, they branch more profusely in homotopic areas and less in heterotopic locations. These branches form axonal columns that are usually in proximity to the border between areas (Mitchell and Macklis, 2005; Courchet et al., 2013; Suarez et al., 2014; Rodriguez-Tornos et al., 2016; Fenlon et al., 2017).

As mentioned, axonal refinement plays an important role in $\mathrm{CC}$ development. On the one hand, postnatal refinement dictates the elimination of exuberant branches that had invaded the cortical plate but do not establish synapses efficiently. This is thought to select optimal functional connectivity (Stanfield et al., 1982; Innocenti and Clarke, 1984; Dehay et al., 1986; Meissirel et al., 1991; Innocenti, 2020). On the other hand, developmental refinement determines the number of CPNs in each area and layer. Early 
in development, CPNs are remarkably exuberant. Many cortical neurons, and virtually all neurons located in the upper layers (L2/3 and L4), develop transient callosal axons that invade the contralateral territories and bear the potential to establish a mature callosal connection. Most of these developmental projections do not progress into mature interhemispheric connections and are instead eliminated during the first postnatal weeks of the animal's life (De Leon Reyes et al., 2019). This CPN refinement is mediated by mechanisms that partly depend on activity, but which are largely unknown (Innocenti and Clarke, 1984; Koralek and Killackey, 1990; Innocenti and Price, 2005; Mizuno et al., 2007; Huang et al., 2013; Suárez et al., 2014; Antón-Bolaños et al., 2019; De Leon Reyes et al., 2019).

In the mouse developing cortex, Neuropilin-1 (Nrp1) is expressed in a high to low mediolateral gradient (Zhao et al., 2011; Zhou et al., 2013; Muche et al., 2015). Nrp1 null mutant mice are embryonically lethal (Kitsukawa et al., 1997). To circumvent lethality, previous studies relied on Nrp1 conditional lines and on mutants of the binding domain of the Semaphorins, which are among its known ligands (Nrp1 ${ }^{\text {Sema- }}$ mutant). Nrp1 plays several roles during CC development (Hatanaka et al., 2009; Zhao et al., 2011; Zhou et al., 2013). At the CC midline, the interaction of Nrp1 with Semaphorin 3 (Sema3) C mediates the crossing of callosal axons (Gu et al., 2003; Niquille et al., 2009; Piper et al., 2009; Mire et al., 2018). Sema3A, another ligand of Nrp1, is expressed in the developing neocortex in a gradient that is opposite and complementary to that of Nrp1 (Tamamaki et al., 2003; Zhao et al., 2011). The binding of Sema3A to Nrp1-PlexinA1 induces axonal repulsion via the collapse of axonal growth cones (Takahashi et al., 1999; Fournier et al., 2000; Wu et al., 2014). Since due to the gradients, callosal axons from motor areas express high Nrp1 and low Sema3A levels, axonal repulsion leads to the segregation of motor and somatosensory (SS) callosal axons, which express the opposite combination (Zhou et al., 2013). This determines that motor and SS axons occupy the dorsal and ventral callosal routes, respectively, and contributes to their guiding to motor and SS contralateral areas. Accordingly, genetic ablations of Sema3A or Nrp1 disrupt this axonal order and disorganizes axonal projections in the contralateral hemisphere (Zhou et al., 2013). This effect is mediated by the steep gradient of Nrp1 expression established between motor and SS areas. However, little is known about the consequences of the lower differences that Nrp1 expression gradient creates within each area. Also, it is not known if Nrp1 plays additional functions on callosal development other than guidance. 
bioRxiv preprint doi: https://doi.org/10.1101/2021.05.12.443798; this version posted May 14, 2021. The copyright holder for this preprint (which was not certified by peer review) is the author/funder, who has granted bioRxiv a license to display the preprint in perpetuity. It is made available under aCC-BY-NC-ND 4.0 International license.

87 Herein we investigated the roles of Nrp1 gradient during the organization of 88 somatosensory interhemispheric maps. 


\section{Results}

\section{Nrp1 expression levels determine the pattern of SS contralateral innervation}

To investigate the roles of Nrp1 in the development of the callosal circuits of the SS cortex, we performed in utero electroporation (IUE) of constructs knocking down (shNrp1) or overexpressing Nrp1 (CAG-Nrp1). IUE was performed at embryonic day (E) 15.5 to specifically target L2/3 neurons. Vectors were co-electroporated with a plasmid encoding GFP (CAG-GFP), thus allowing to characterize the electroporated neurons and their projections at selected stages after birth (Figure 1A). Electroporations were targeted to the SS cortex, which is functionally divided into the primary somatosensory cortex (S1) and the secondary somatosensory cortex (S2), which receives first and higher-order sensory inputs from the thalamus, respectively (Rakic, 1988; Watson, 2012). For the analyses, the S1 barrel field area and the more lateral S2 area (Figure 1B) were distinguished by anatomical hallmarks such as the high density of L4 DAPI ${ }^{+}$nuclei in the barrels (Paxinos and Franklin, 2004). We first examined the effects of our Nrp1 manipulations on the mature circuit of postnatal day (P) 30 animals. Coronal sections of brains electroporated with the control plasmid (CAG-GFP) showed that callosal projections from $\mathrm{GFP}^{+} \mathrm{L} 2 / 3$ neurons reproducibly elaborate separated axonal columns in the SS areas of the contralateral hemisphere as described (Courchet et al., 2013; Suárez et al., 2014). The main column is located at the border of the S1 and S2 area, hereafter referred to as S1/S2 column (Figure 1A-C, blue arrowheads). Another less dense but very similar column forms in the lateral border of S2, hereafter referred to as the S2 column (Figure 1A-C, magenta arrowheads). Within the S1/S2 column, axons branch more profusely in L2/3 and L5, and within the S2 column, in L2/3 (Figure 1C). When knocking down Nrp1, we did not advert any obvious change in the overall pattern of contralateral innervation (Figure 1D). By contrast, overexpressing Nrp1 in L2/3 neurons caused a visible reduction of $\mathrm{S} 2$ axons together with an increase of S1 innervation (Figure 1E). To quantify these phenotypes, we measured the pixels occupied by the GFP fluorescence signal in specific regions of interest (ROI) delineating the main relevant SS areas and columns. To account for any differences in electroporation efficiency, the values of GFP within these ROIs were normalized to the fluorescence signal of the ipsilateral hemisphere (see Methods) (Rodriguez-Tornos et al., 2016; Briz et al., 2017). Firstly, the analysis of the total contralateral innervation showed that the average values and dispersion are indistinguishable in controls, shNrp1, and CAG-Nrp1 conditions (Figure 
122 1F). This result confirmed that changing Nrp1 levels does not cause overall impairments

123 of axonal innervation. Secondly, we quantified the number of $\mathrm{GFP}^{+}$branches forming the

$124 \mathrm{~S} 1 / \mathrm{S} 2$ column (Figure 1G), the S2 column (Figure 1H), and the axons in the remaining

$125 \mathrm{~S} 1$ area (Figure 1I). This quantification revealed a reduced S2 column and a slight

126 increase of $\mathrm{GFP}^{+}$axons in $\mathrm{S} 1$ in CAG-Nrp1 electroporated brains. No differences were

127 detected in brains electroporated with shNrp1 (Figure 1G-I). An alternative analysis of

128 the relative distribution of $\mathrm{GFP}^{+}$axons in the different contralateral areas rendered

129 equivalent results (See Methods and Figure 1 - figure supplement 1). The differences in

130 axonal distribution were not due to neuronal death because the proportions of ipsilateral

$131 \mathrm{GFP}^{+}$neurons were indistinguishable in brains of all conditions (Figure 1 - figure

132 supplement 2). Thus, increasing Nrp1 levels in L2/3 neurons blocks the development of

133 their callosal axons in the contralateral S2 area while promoting branching in S1

134 territories. This suggests the implication of Nrp1 in the area-specific distribution of

135 callosal branches. 
bioRxiv preprint doi: https://doi.org/10.1101/2021.05.12.443798; this version posted May 14, 2021. The copyright holder for this preprint (which was not certified by peer review) is the author/funder, who has granted bioRxiv a license to display the preprint in perpetuity. It is made available under aCC-BY-NC-ND 4.0 International license.

\section{Figure 1}

A
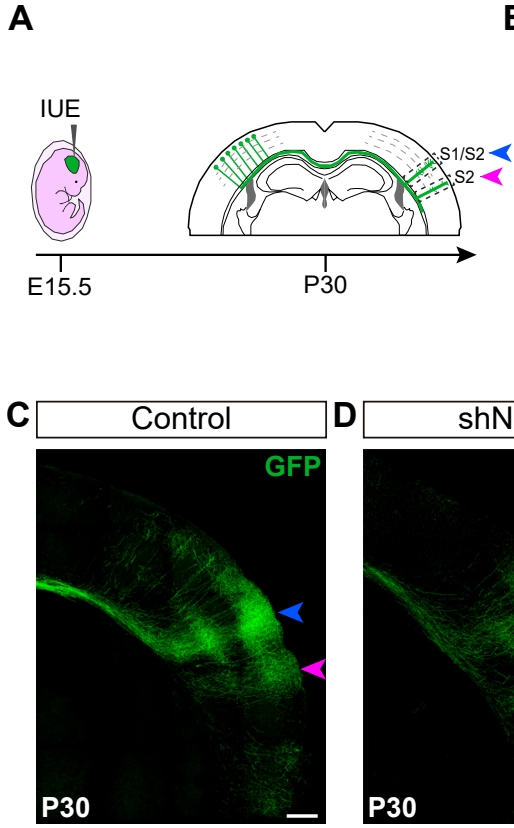

B

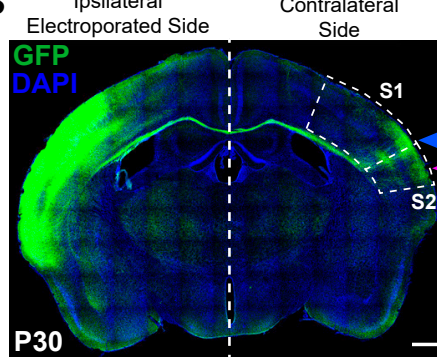

$\mathbf{F}$
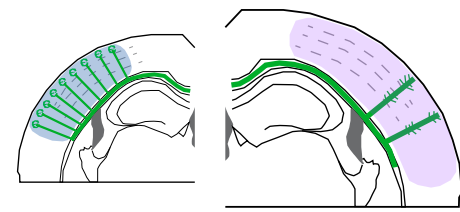

S1/S2 column relative to ipsilateral somas

$\mathbf{G}$
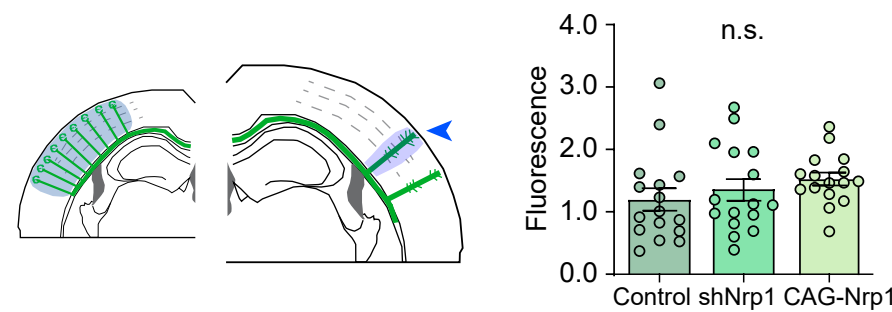

H

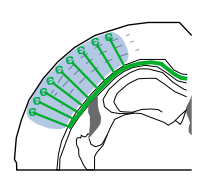

I

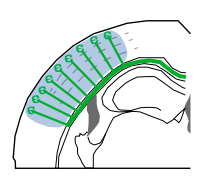

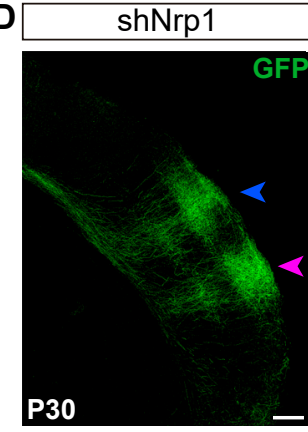

$\mathbf{E}$

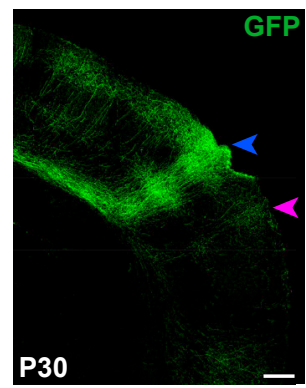

GFP

(a) cor
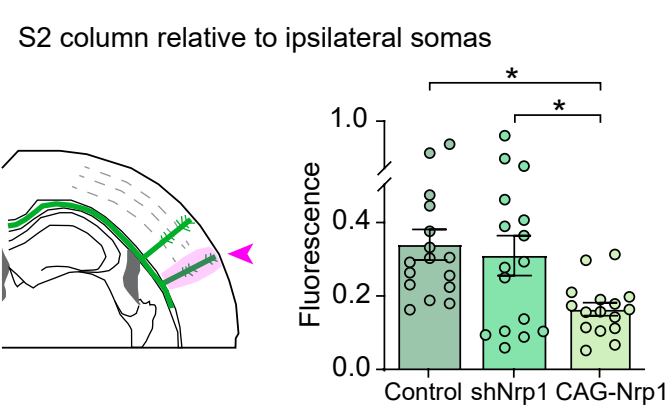

$\mathrm{S} 1$ area relative to ipsilateral somas

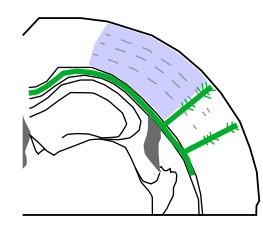
(shaded areas). Graphs show values of GFP innervation relative to the fluorescence signal in the ipsilateral electroporated side of the same coronal section to normalize to the number of IUE L2/3 neurons. Mean \pm SEM $(n=8$ brains, 2 sections per brain, in all conditions). S1/S2 column (blue arrow), S2 column (magenta arrow). F) The innervation in the contralateral SS area. (One-way ANOVA: $P$-value $=0.6625$ (n.s.)). G) $\mathrm{S} 1 / \mathrm{S} 2$ column (One-way ANOVA: $P$-value $=0.3478$ (n.s.)). H) S2 column (One-way ANOVA: $P$-value $=0.0085(* *)$. Posthoc with Tukey's test: $* p$-value control-CAG-Nrp1 $=$ $0.0106, * p$-value shNrpl - CAG-Nrp1 $=0.0393)$. I) $\mathrm{S} 1$ area (One-way ANOVA: $P$-value $=0.0129\left(^{*}\right)$. Posthoc with Tukey's test: $* * p$-value Control-CAG-Nrpl $=0.0095)$.

Figure 1. Analysis of the distribution of callosal axons upon alterations in Nrp1 levels. A) Scheme of the experimental approach. Contralaterally, L2/3 callosal Coronal section of P30 control brain electroporated at secondary somatosensory cortex (S2) (dashed boxes). Green $=$ GFP, Blue $=$ DAPI. Scale bar $=500 \mu \mathrm{m}$. C-E) High magnifications of the contralateral hemisphere of P30 IUE brains showing $\mathrm{GFP}^{+}$(green) axons of S1/S2 (blue arrow) and $\mathrm{S} 2$ columns (magenta arrow). Scale bar $=$ $00 \mu \mathrm{m}$. F-I) Quantification of axonal distribution in the contralateral hemisphere. The left panels depict schemes showing the selected ROIs in which $\mathrm{GFP}^{+}$is quantified (blue arrow) and the S2 column (magenta arrow). B) functional areas: primary somatosensory cortex (S1) and 


\section{Nrp1 levels orchestrate callosal homotopic innervation in the somatosensory areas}

137 We next analyzed the topographic location of the electroporated CPNs projecting to S1

138 or S2. Using stereotaxic coordinates, we performed classic axonal retrograde tracing by 139 injecting fluorescent conjugates of cholera toxin subunit B of (CTB-555) in the cortical 140 plate of the non-electroporated hemisphere. This procedure labels the subset of neurons 141 projecting to the site of injection (Figure 2A). We injected P28 animals either in the S1 142 area, at the level of the S1/S2 column (Figure 2A-B), or in the S2 column (Figure 2A and $143 \mathrm{C}$ ), and we analyzed the location of the $\mathrm{GFP}^{+} \mathrm{CTB}^{+} \mathrm{L} 2 / 3 \mathrm{CPNs}$ at P30 (Figure 2A). As a retrospective control of the injection site, we confirmed that, in addition to cortical neurons, our injections in the S1/S2 column labeled preferentially thalamic neurons of the ventral posteromedial nuclei (VPM) (Figure 2 - figure supplement 1A-C), while our injections in the S2 column labeled neurons of the posterior nucleus (Po) (Figure 2 figure supplement 1D-F) (see Methods). After counting the CPNs, we calculated the relative distribution of CPNs in $\mathrm{S} 1$ and $\mathrm{S} 2$ to evaluate changes in their contralateral targeting. For injections in the S1/S2 column, we calculated the ratio of $\mathrm{GFP}^{+} \mathrm{CTB}^{+}$ neurons in S1 vs. the number in S2 (homotopic projections vs. heterotopic projections). This analysis showed that in controls, most axons that form the S1/S2 column are homotopic projections from S1 since S1L2/3 CPNs were labeled 1.5 times more frequently than those in S2 (Figure 2D and J). Although there was a tendency to small decreases in the labeling of S1 CPNs, we observed no significant changes in shNrp1 or CAG-Nrp1 populations (Figure 2E-F and J). Hence, S1 innervation is not majorly affected by our manipulations. For animals injected in the S2 column, we calculated the ratio of $\mathrm{GFP}^{+} \mathrm{CTB}^{+}$neurons found in $\mathrm{S} 2$ (homotopic) vs. those labeled in $\mathrm{S} 1$ (heterotopic) (Figure 2G-I, and K). This analysis showed that in controls, homotopic S2L2/3 projections are the main contributors to the $\mathrm{GFP}^{+} \mathrm{S} 2$ column (2,5 ratio) (Figure $2 \mathrm{G}$ and K). Both knocking down or overexpressing Nrp1 decreased the proportions of S2L2/3 CPNs labeled with CTB injected in contralateral S2 (Figure 2H-I and K). The decreases observed in shNrp1 IUE brains indicated that their $\mathrm{GFP}^{+} \mathrm{S} 2$ column is formed by an excess of heterotopic S1L2/3 axons (Figure 1D and H). Thus, the growth of shNrp1 S1L2/3 callosal branches compensates for the loss of Nrp1-deficient homotopic S2L2/3 projections. For the CAG-Nrp1 animals, since we had observed a reduction of the GFP ${ }^{+}$ S2 column (Figure 1E, and H), the data confirmed the loss of homotopic S2L2/3 branches. 
169 were not the consequence of differences in labeling efficiency, as we detected no changes

170 in the distributions of non-electroporated $\mathrm{CTB}^{+}$cells between conditions (Figure 2 -

171 figure supplement 2). In sum, knocking down Nrp1 expression impairs the development

172 of homotopic S2L2/3 callosal projections but is insufficient to trigger this effect in more

173 medial S1L2/3 neurons. Contrary, incrementing Nrp1 expression blocks the development

174 of both S1L2/3 and S2L2/3 branches into S2 equally, resulting in a diminished S2 column

175 formed by an equilibrated proportion of S1L2/3 and S2L2/3 projections. These findings

176 demonstrate that the gradient of Nrp1 expression favors homotopic SSL2/3 callosal

177 connectivity. 
bioRxiv preprint doi: https://doi.org/10.1101/2021.05.12.443798; this version posted May 14, 2021. The copyright holder for this preprint (which was not certified by peer review) is the author/funder, who has granted bioRxiv a license to display the preprint in perpetuity. It is made available under aCC-BY-NC-ND 4.0 International license.

Figure 2

A

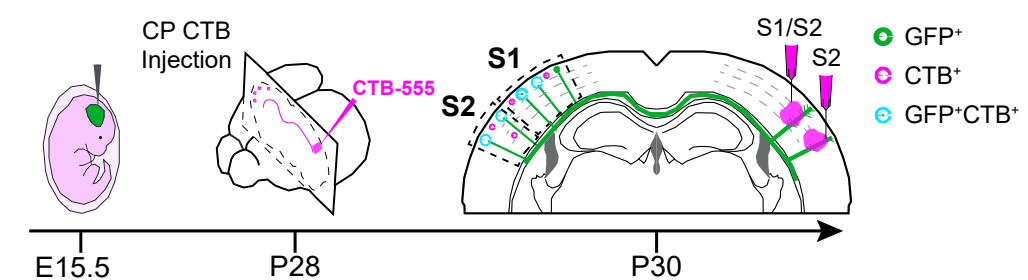

B
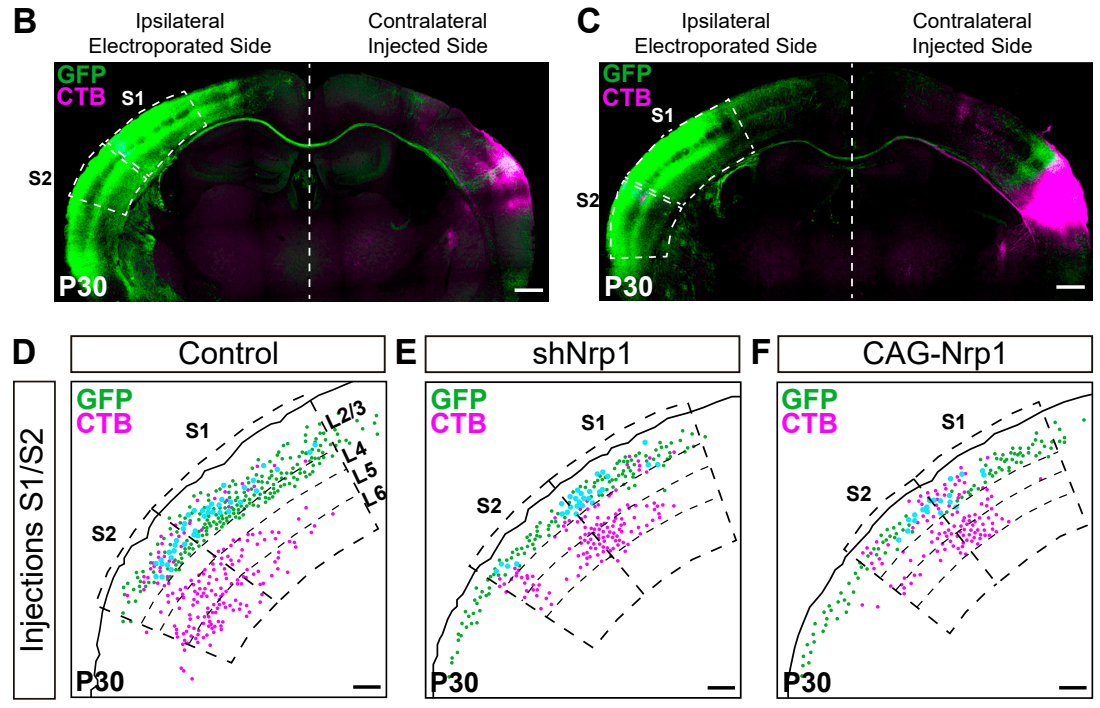

H
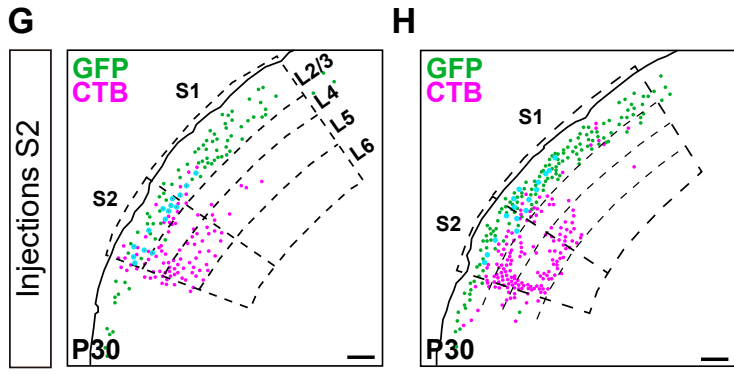

Distribution of CPNs

$\mathbf{J}$ Injections in S1/S2 column

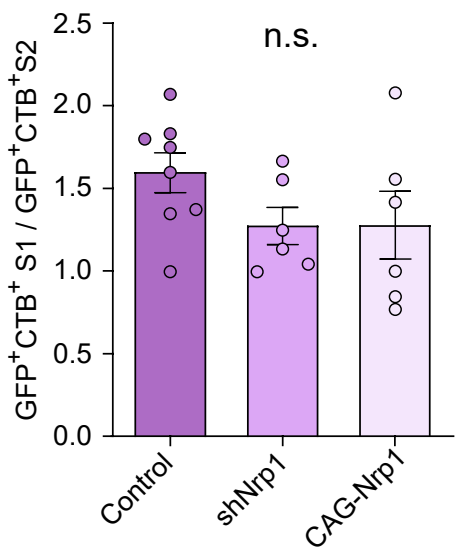

K

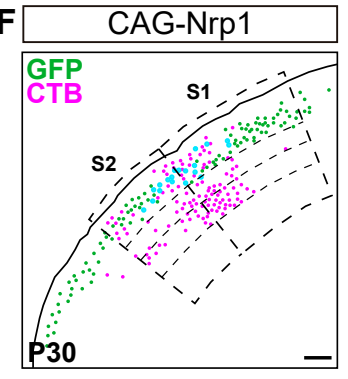

I

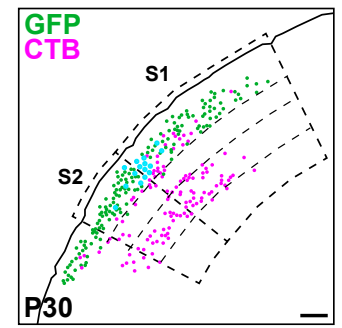

Figure 2. Analysis of homotopic and heterotopic projections in control, shNrp1, and CAG-Nrp1 IUE brains. A) Experimental workflow. After IUE at E15.5, brains are stereotaxically injected with CTB in CP at P28. Separate animals are injected in the $\mathrm{S} 1 / \mathrm{S} 2$ column or the S2 column. Then, the numbers of $\mathrm{GFP}^{+} \mathrm{CTB}^{+} \mathrm{CPNs}$ are quantified in $\mathrm{S} 1$ and $\mathrm{S} 2$ in the ipsilateral electroporated hemisphere at P30. B-C) Tilescan images of P30 coronal sections of control IUE brains injected in $\mathrm{S} 1 / \mathrm{S} 2$ (B) or S2 coordinates $(\mathrm{C})$. On the left, the ipsilateral side, where $\mathrm{GFP}^{+}$and $\mathrm{CTB}^{+}$somas are found. On the right, the contralateral hemisphere, the site of injections. Green = GFP, Magenta $=$ CTB-555. Scale bar $=500 \mu \mathrm{m}$. D-I) Schemes reporting examples of the location of $\mathrm{GFP}^{+}$neurons (green dots), $\mathrm{CTB}^{+}$neurons (magenta dots), and $\mathrm{GFP}^{+} \mathrm{CTB}^{+}$(blue dots) in coronal sections of IUE brains injected with CTB in the cortical plate. Scale bar $=300 \mu \mathrm{m}$. J) Quantification of the distribution of $\mathrm{GFP}^{+} \mathrm{CTB}^{+}$after brains were injected in the S1/S2 column. Ratio (Y-axis) of the number of $\mathrm{GFP}^{+} \mathrm{CTB}^{+}$in $\mathrm{S} 1$ divided by the number of $\mathrm{GFP}^{+} \mathrm{CTB}^{+}$cells in $\mathrm{S} 2$ quantified in individual sections. Mean $\pm \operatorname{SEM}(\mathrm{n} \geq 3$ brains, 2 sections per brain in all conditions. One-way ANOVA: $P$-value $=0.2096$ (n.s.)). K) Quantification of the distribution of $\mathrm{GFP}^{+} \mathrm{CTB}^{+}$after brains were injected in S2. Ratio (Y-axis) of the number of $\mathrm{GFP}^{+} \mathrm{CTB}^{+}$in $\mathrm{S} 2$ divided by the number of $\mathrm{GFP}^{+} \mathrm{CTB}^{+}$cells in $\mathrm{S} 1$ quantified in individual sections. Mean $\pm \operatorname{SEM}(\mathrm{n} \geq 3$ brains, 2 sections per brain in all conditions. One-way ANOVA: $P$-value $=0.0036(* *)$. Posthoc with Tukey's test: $* * p$-value Control - shNrp1 $=0.0052 ; *$ $p$-value Control-CAG-Nrp1 $=0.0109$ ). 
178 Changes in Nrp1 expression alter developmental growth and refinement of callosal projections

180 Next, we investigated the mechanisms responsible for the different topography of callosal

181 connectivity in Nrp1 electroporated P30 brains. To do so, we analyzed the innervation of 182 P16 electroporated animals and compared them to P30. P16 control electroporated brains 183 showed recognizable S1/S2 and S2 axonal columns, and quantifications demonstrated a 184 distribution of contralateral branches very similar to that of P30 animals (Figure 3A, D185 G). In contrast, P16 brains electroporated with shNrp1 or CAG-Nrp1 constructs showed 186 reduced branching when compared to either P16 or P30 controls (Figure 3A-G). These 187 reductions were observed throughout all contralateral areas (Figure 3 - figure supplement 188 1), although they were higher in S2 (Figure 3F). Besides, in controls, contralateral 189 branches decreased from P16 to P30 (Figure 3D-F) as a consequence of the final pruning 190 of callosal connections (O'Leary, 1992; De Leon Reyes et al., 2019), but in shNrp1 and 191 CAG-Nrp1 electroporated brains, axonal growth followed the opposite trend. 192 Contralateral branches increased in all areas from P16 to P30, except in the S2 of CAG193 Nrp1 brains (Figure 3D-G). Thus, abnormally late postnatal axonal growth compensates 194 for the delayed contralateral innervation detected at P16, although with an incorrect 195 topographic organization as revealed by our CTB labeling of CPNs. 
bioRxiv preprint doi: https://doi.org/10.1101/2021.05.12.443798; this version posted May 14, 2021. The copyright holder for this preprint (which was not certified by peer review) is the author/funder, who has granted bioRxiv a license to display the preprint in perpetuity. It is made available under aCC-BY-NC-ND 4.0 International license.

\section{Figure 3}
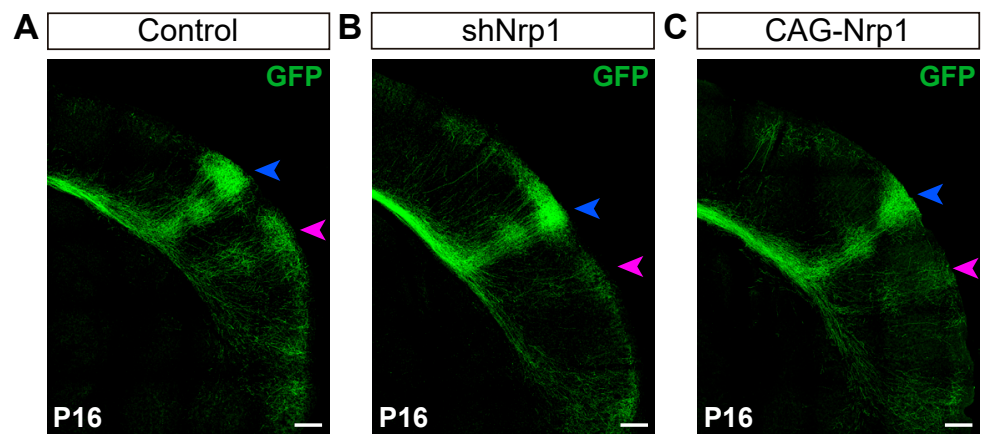

D Contralateral innervation relative to
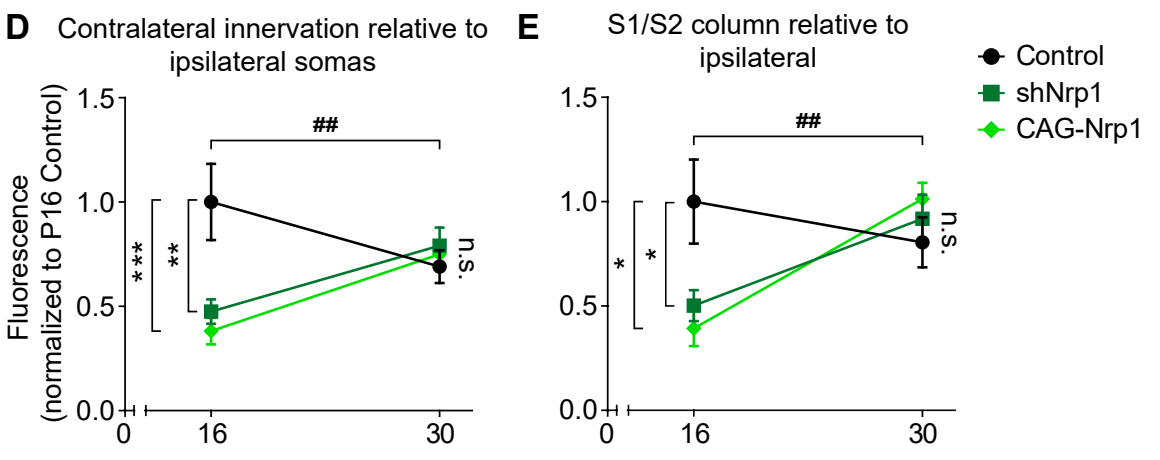

F $\quad$ S2 column relative to ipsilateral

G S2 column relative to $\mathrm{S} 1 / \mathrm{S} 2$
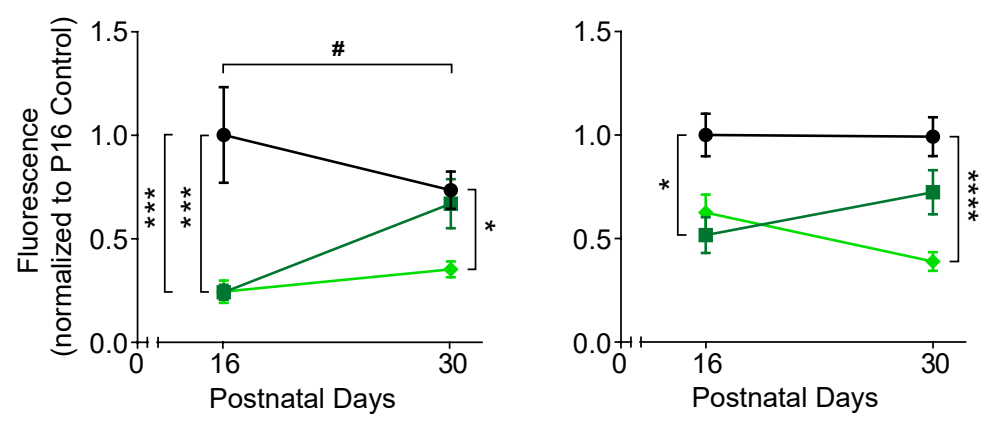

Figure 3. Comparisons of the postnatal changes of contralateral axons during the P16 to $P 30$ window upon manipulations in Nrp1 expression. A-C) High magnification tilescan images of the contralateral hemisphere of IUE brains analyzed at P16 (Blue arrow $=\mathrm{S} 1 / \mathrm{S} 2$ column. Magenta arrow $=\mathrm{S} 2$ column. Green $=$ GFP). Scale bar $=300 \mu \mathrm{m}$. D-G) Plots of ratios of $\mathrm{GFP}^{+}$innervation in the indicated area, relative to ipsilateral IUE hemisphere and normalized to the value of P16 control. Mean \pm SEM ( $\mathrm{n} \geq 4$ brains, 2 sections per brain in all conditions). D) Contralateral innervation in all SS area (Two-way ANOVA: $P$-value Dynamics of contralateral innervation $=0.0012(\# \#) ; P$-value Postnatal day $=0.1224 ; P$-value Experimental condition $=0.0149$. Posthoc with Tukey's test: $* * p$-value Control P16-shNrp1 P16 $=0.0044 ; * * * p$-value Control P16-CAG-Nrp1 P16 $=0.0007)$. E) S1/S2 column (Two-way ANOVA: $P$-value Dynamics of S1/S2 column $=0.0052(\# \#)$; $P$-value Postnatal day $=0.0080 ; P$-value Experimental condition $=0.2043$. Posthoc with Tukey's test: * $p$-value Control P16- shNrp1 P16 $=0.0465 ; * p$-value Control P16-CAG-Nrp1 P16 $=0.0116) . \mathrm{F}) \mathrm{S} 2$ column (Two-way ANOVA: $P$-value Dynamics of S2 column $=0.0114(\#) ; P$-value Postnatal day $=0.3331 ; P$-value Experimental condition $<0.0001$. Posthoc with Tukey's test: $* * * p$-value Control P16 - shNrpl P16 $=0.0003$; $* * * p$-value Control P16-CAG-Nrp1 P16 $=0.0003 ; * p$-value Control P30-CAG-Nrp1 P30 $=0.0123) . \mathrm{G}) \mathrm{S} 2$ column relative to $\mathrm{S} 1 / \mathrm{S} 2$ column (Two-way ANOVA: $P$-value Dynamics $\mathrm{S} 2$ column relative to $\mathrm{S} 1 / \mathrm{S} 2$ column $=$ 0.2098 (n.s.); $P$-value Postnatal day $=0.8770 ; P$-value Experimental condition $<0.0001$. Posthoc with Tukey's test: $* p$-value Control P16-shNrp1 P16 $=0.0102 ; * * * * p$-value Control P30-CAG-Nrp1 P30 $<0.0001$ ). Data for P30 are from Figure 1 and Figure 1 - Figure supplement 1. 
196 Nrp1 levels determine the postnatal refinement of somatosensory L2/3 callosal axons

\section{7 at the midline}

198 The CC organizes following dorsal-ventral topography. Decreasing Nrp1 expression in

199 cortical motor neurons shifts callosal axon navigation to the ventral routes used by SS

200 projections (Zhou et al., 2013). Therefore, we analyzed the distribution of electroporated

201 axons at the CC midline by quantifying the signal of $\mathrm{GFP}^{+}$axons and plotting it against

202 the dorso-ventral length of the $\mathrm{CC}$ divided into ten equal bins (Figure 4A). These analyses

203 were performed at P16 and P30. In control, shNrp1 and CAG-Nrp1 electroporated brains,

204 SS callosal projections crossed the midline by the most ventral two-thirds parts of the CC

205 (bins 1-7) at both developmental stages. Only a few axons navigated by the most dorsal

206 pathway (bins 7-10) (Figure 4B-I). Control, shNrp1, and CAG-Nrp1 P16 distributions

207 were very similar, showing small differences in bins 3 and 5 (Figure 4B-E). Differences

208 increased at $\mathrm{P} 30$. $\mathrm{GFP}^{+}$callosal axons occupied slightly more dorsal routes (bins 4-10) in

209 shNrp1 and CAG-Nrp1 electroporated brains than in controls (Figure 4F-I). We then

210 compared, for each condition, the distributions at P16 and P30. This analysis revealed

211 developmental changes. It showed that in controls, callosal axons that cross through the

212 most dorsal paths (bins 3-8) are refined from P16 to P30, which suggests a topographic

213 developmental elimination of interhemispheric projections (Figure 4B, F and J). This

214 elimination of midline axons was reduced in shNrp1 electroporated brains, especially of

215 those using dorsal routes (Figure 4K). Remodeling was not detected in CAG-Nrp1

216 electroporated brains (Figure 4L). The results suggested that changes in Nrp1 levels

217 modify the developmental elimination of topographically organized callosal connections. 
bioRxiv preprint doi: https://doi.org/10.1101/2021.05.12.443798; this version posted May 14, 2021. The copyright holder for this preprint (which was not certified by peer review) is the author/funder, who has granted bioRxiv a license to display the preprint in perpetuity. It is made available under aCC-BY-NC-ND 4.0 International license.

Figure 4

A

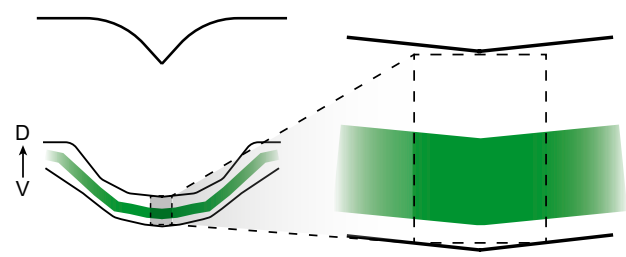

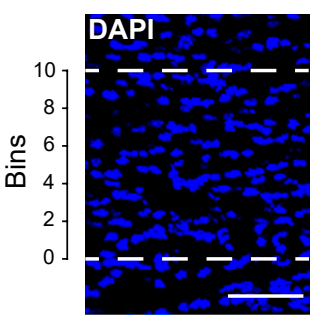

GFP

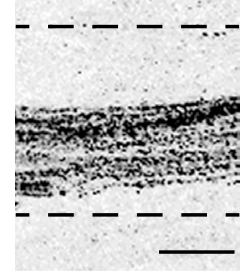

B
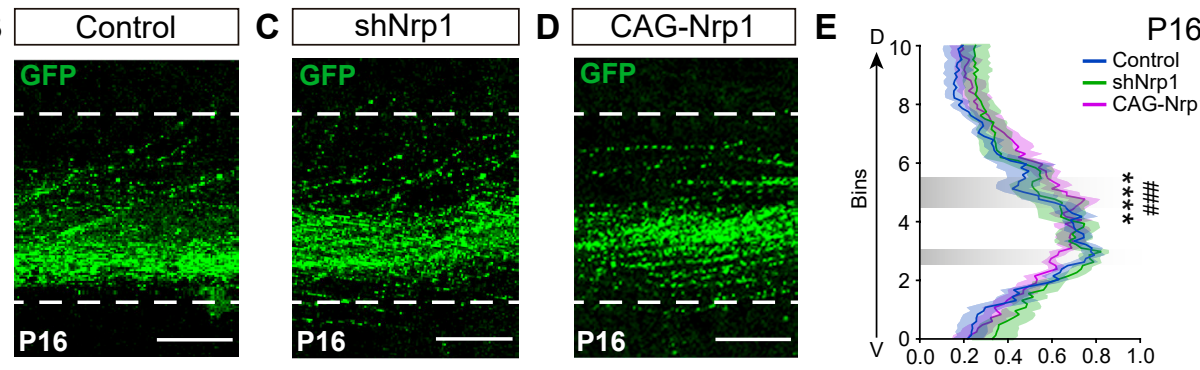

$\mathbf{F}$

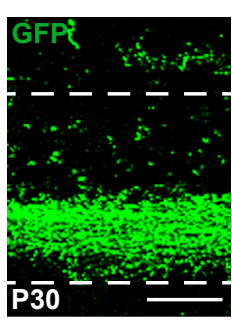

G

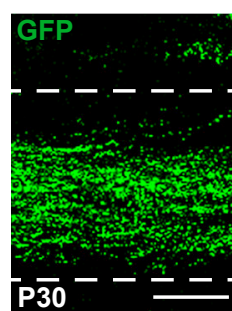

H
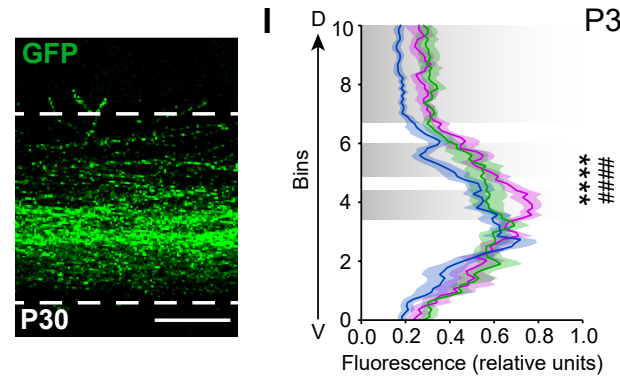

J

Control

K

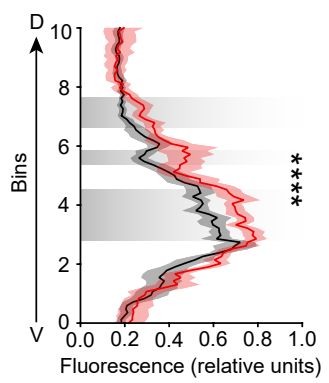

shNrp1

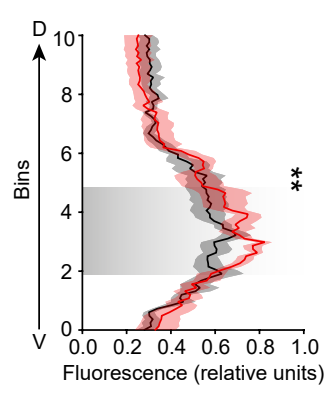

$\mathbf{L}$

CAG-Nrp1

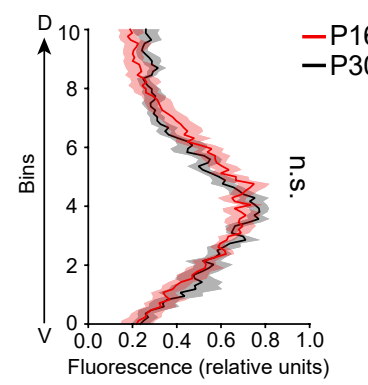

Figure 4. Analysis of the dorsoventral distribution of axons at the midline. A) Scheme of the analysis. The left panel depicts the selected ROI. The right panel shows the ROI divided into ten equal bins and applied to an image of the midline. DAPI image (blue) and pixels occupied by the GFP axons (grey). Scale bar $=50 \mu \mathrm{m}$. B-D) Images of the CC at the midline in P16 brains. (Green $=\mathrm{GFP}$ ). Scale bar $=50 \mu \mathrm{m}$. E) Quantification of the dorsoventral distribution of GFP signal at P16 (ventral position, bins 0 ; dorsal position, bins 10$)$. Lines represents mean $\pm \mathrm{SEM}$ (shade) $(\mathrm{n} \geq 3$ brains, 2 sections per brain in all conditions). Shaded areas in grey indicate statistically significant differences (Two-way ANOVA: $P$-value $\mathrm{cc}$ distribution $=0.9992 ; P$-value Bins $<0.0001 ; P$-value Experimental condition $<0.0001$. Posthoc with Tukey's test: $* * * * p$-value control - shNrpl $\leq 0.0001$; \#\#\# $p$-value controlCAG-Nrpl $=0.0006)$. F-H) Images of the CC at the midline in P30 brains (Green $=$ GFP). Scale bar $=$ $50 \mu \mathrm{m}$. I) Quantification of the dorsoventral distribution of GFP signal at P30 (ventral position, bins 0 ; dorsal position, bins 10). Lines represents mean $\pm \operatorname{SEM}$ (shade) ( $\mathrm{n} \geq 3$ brains, 2 sections per brain in all conditions). Shaded areas in grey indicate bins showing statistically significant differences (Two-way ANOVA: $P$-value $\mathrm{Cc}_{\text {distribution }}=0.9925 ; P$-value Bins $<0.0001 ; P$-value Experimental condition $<$ 0.0001 . Posthoc with Tukey's test: $* * * * p$-value Control-shNrp1 $<0.0001$; \#\#\# $p$-value Control-CAG-Nrp1 $<$ 0.0001). J-L) Comparison of the distributions of axons at the CC in P16 and P30 brains. Lines represents mean \pm SEM (shade) ( $\mathrm{n} \geq 3$ brains, 2 sections per brain in all conditions). J) Control (Two-way ANOVA: $P$-value $<0.0001(* * * *)$ ). K) shNrp1 (Two-way ANOVA: $P$-value $=0.0021$ $(* *))$. L) CAG-Nrp1 (Two-way ANOVA: $P$-value $=0.5513$ (n.s.)). 


\section{Knocking down Nrp1 eliminates populations of S2L2/3 CPNs by refinement}

219 Our results suggested that Nrp1 influences refinement. We recently showed that as part 220 of their normal differentiation, L2/3 neurons first develop axons that project callosally, 221 and subsequently, postnatal activity-dependent refinement eliminates most of these 222 developmental callosal axons in area-specific manners, thereby selecting the populations 223 of adult CPNs. The most intensive refinement of L2/3 CPNs occurs during the first two weeks of postnatal life (P1-P16). From then on, the proportion of L2/3 CPNs is very similar to that of the adult (De Leon Reyes et al., 2019). To investigate a possible influence of Nrp1 in developmental CPN refinement, we set to analyze CPN numbers in the SS cortex of control and Nrp1 electroporated brains at P16 and P30. To this end, instead of in the cortical plate, we injected CTB-555 directly in the CC in the hemisphere opposite to the electroporation (Figure 5A-C). This procedure labels all neurons with an axon crossing the midline, including those in the process of developing or refining their callosal projections (De Leon Reyes et al., 2019). In controls, after the injections, quantifications showed proportions of S1L2/3 and S2L2/3 CPNs undistinguishable to those previously reported in P16 and P30 WT mice, indicating that IUE does not alter CPN development (Figure 5 - figure supplement 1-2) (Fame et al., 2011; De Leon Reyes et al., 2019). Refinement of L2/3 CPNs, in both $\mathrm{S} 1$ and $\mathrm{S} 2$ areas, was not altered upon overexpression of Nrp1. However, electroporation of shNrp1 modified refinement (Figure 5 D-I). In P16 control brains, $50 \%$ of $\mathrm{GFP}^{+} \mathrm{S} 1 \mathrm{~L} 2 / 3$ neurons were $\mathrm{CTB}^{+}$(CPNs) (Figure 5D and E). This number increased to 65\% in shNrp1-targeted S1L2/3 (Figure 5D and $\mathrm{F}$ ), indicating that low $\mathrm{Nrp} 1$ expression delays axonal refinement. In $\mathrm{S} 2,40 \%$ of GFP ${ }^{+}$ $\mathrm{L} 2 / 3$ cells were $\mathrm{CTB}^{+}$in controls or shNrp1 P16 electroporated brains (Figure 5G). Thus, since the numbers of P16 L2/3CPNs in these brains are equal or higher than in controls, the reduced $\mathrm{GFP}^{+}$innervation that we observed in shNrp1 or CAG-Nrp1 electroporated brains is due to the scarce branching of $\mathrm{GFP}^{+} \mathrm{L} 2 / 3$ axons in the contralateral cortical plate. At $\mathrm{P} 30,45 \%$ of $\mathrm{GFP}^{+} \mathrm{S} 1 \mathrm{~L} 2 / 3$ and around $36 \%$ of $\mathrm{GFP}^{+} \mathrm{S} 2 \mathrm{~L} 2 / 3$ control neurons were CPNs (Figure 5D and G). In shNrp1 P30 brains, the percentage of $\mathrm{GFP}^{+}$S1L2/3 CPNs was indistinguishable from controls (Figure 5D) but the proportion of S2L2/3 CPNs was significantly reduced (Figure 5G-I). Thus, on the one hand, late postnatal refinement normalizes the transient increases of P16 S1L2/3 CPNs induced by knocking down Nrp1. On the other hand, refinement causes the exceeding elimination of S2L2/3 CPNs resulting in a significant decrease of their final numbers in the mature P30 circuit. Together, the 
bioRxiv preprint doi: https://doi.org/10.1101/2021.05.12.443798; this version posted May 14, 2021. The copyright holder for this preprint (which was not certified by peer review) is the author/funder, who has granted bioRxiv a license to display the preprint in perpetuity. It is made available under aCC-BY-NC-ND 4.0 International license.

251 data shows that by regulating axonal growth and refinement, Nrp1 levels determine 252 homotopic callosal connectivity.

Figure 5

A

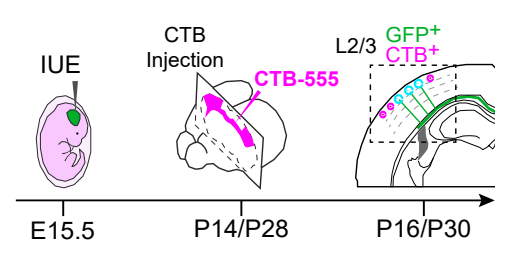

B

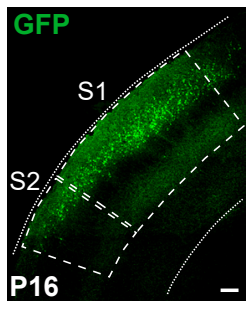

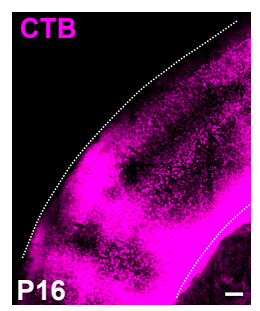
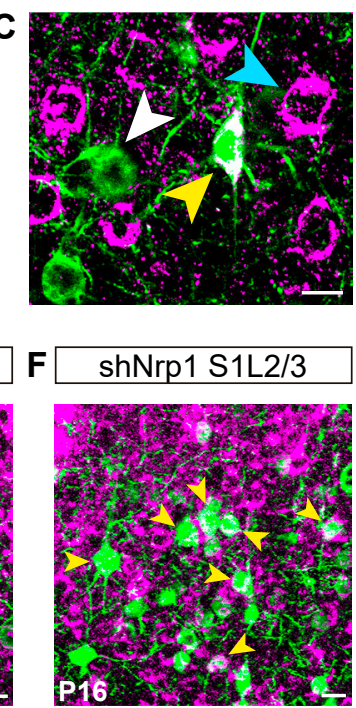

- Control

- shNrp1

$\rightarrow$ CAG-Nrp1
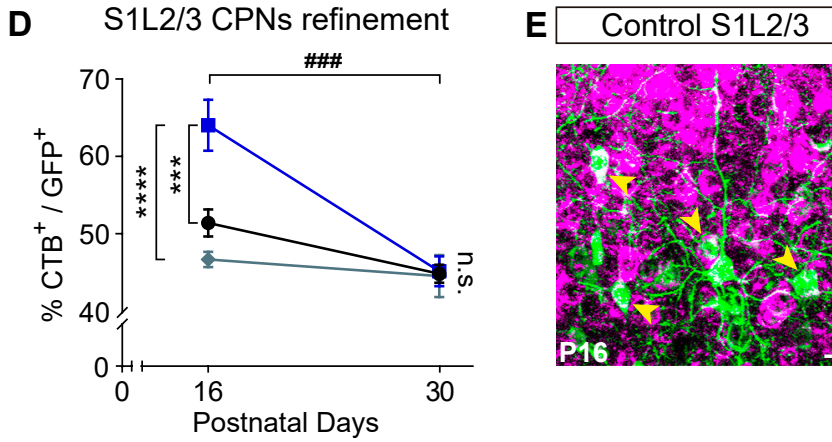

G

S2L2/3 CPNs refinement

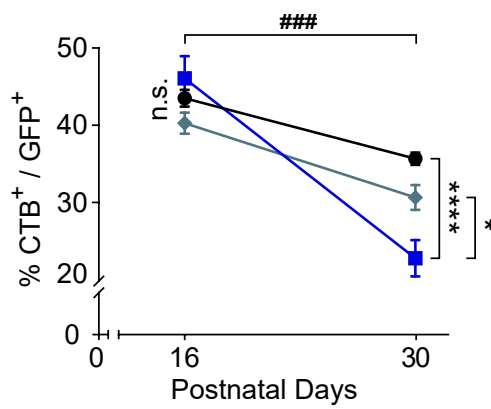

shNrp1 S2L2/3
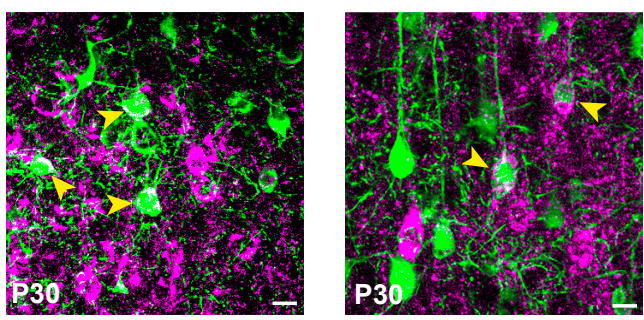

Figure 5: CPNs refinement during development (P16 to P30). A) Scheme of the experimental workflow. To analyze the effect of developmental refinement on the number of electroporated CPNs, stereotaxic CTB injection at the midline was performed after IUE at E15.5. B) Images showing ipsilateral cortex of P16 brains (delimitated by dashed lines). Left panel shows $\mathrm{GFP}^{+}$electroporated neurons. Right panel shows the signal of CTB labeling axonal columns and somas $($ Green $=$ GFP. Magenta $=$ CTB-555). Scale bar $=300 \mu \mathrm{m}$. C) High magnification image of $\mathrm{GFP}^{+} \mathrm{L} 2 / 3$ neurons in an injected P16 brain $\left(\mathrm{GFP}^{+}\right.$, white arrowhead), $\left(\mathrm{CTB}^{+}\right.$, blue arrowhead), $\left(\mathrm{GFP}^{+} \mathrm{CTB}^{+}\right.$, yellow arrowhead). Scale bar $=10 \mu \mathrm{m}$. D) Plot of the proportion of $\mathrm{CPNs}\left(\mathrm{GFP}^{+} \mathrm{CTB}^{+} / \mathrm{GFP}^{+}\right)$in $\mathrm{S} 1$ area at $\mathrm{P} 16$ and $\mathrm{P} 30$. Mean \pm SEM ( $\mathrm{n} \geq 3$ brains, 2 sections per brain in all conditions). (Two-way ANOVA: $P$-value siL2/3 cPNs refinement $=0.0007(\# \# \#) ; P$-value Postnatal day $<0.0001 ; P$-value Experimental condition $=0.0003$. Posthoc with Tukey's test: $* * * p$-value Control P16-shNrp1 P16 $=0.0003 ; * * * * p$-value shNrp1 P16-CAG-Nrp1 P16 < 0.0001). E-F) Merge images of control (E) and shNrp1 (F) S1L2/3 neurons at P16 (GFP $\mathrm{CTB}^{+}$, yellow arrowheads). Scale bar $=10 \mu \mathrm{m}$. G) Plot of the proportion of CPNs $\left(\mathrm{GFP}^{+} \mathrm{CTB}^{+} / \mathrm{GFP}^{+}\right)$in $\mathrm{S} 1$ area at $\mathrm{P} 16$ and $\mathrm{P} 30$. Mean $\pm \mathrm{SEM}(\mathrm{n} \geq 3$ brains, 2 sections per brain in all conditions). (Two-way ANOVA: $P$-value s2L2/3 CPNs refinement $=0.0003(\# \#$ ); $P$-value Postnatal day $<0.0001 ; P$-value Experimental condition $=$ 0.0199. Posthoc with Tukey's test: $* * * *$-value Control P30-shNrpl P30 $<0.0001 ; * p$-value shNrp1 P30-CAG-Nrp1 P30 $=0.0127)$. H-I) Merge images of control (E) and shNrp1 (F) S1L2/3 neurons at P16 (GFP ${ }^{+} \mathrm{CTB}^{+}$, yellow arrowheads). Scale bar $=10 \mu \mathrm{m}$. 


\section{Discussion}

254 We herein demonstrate that, in the SS cortex, the Nrp1 gradient determines the topographic organization of SSL2/3 callosal connections. Nrp1 promotes homotopic branching and hinders heterotopic innervation (Figure 6). Previous studies have shown that the Nrp1 gradient in the cortex regulates an orderly organization of motor and SS axons during early postnatal development (Zhou et al., 2013). We find that in addition to this function, Nrp1 regulates the late growth, branching, and terminal refinement of callosal axons. S1 and S2 areas process distinct somatosensory information received from first-order and higher-order thalamic nuclei (Inan and Crair, 2007; Pouchelon et al., 2014). Thus, Nrp1 mediates a hierarchical organization of the bilateral exchange of sensory inputs. Our findings highlight the complex regulation required for the wiring of interhemispheric cortical maps.

We demonstrate that Nrp1 functions regulate the late development of callosal axonal branches. Our results argue in favor of possible mechanisms of competition or axonal cooperation, which are poorly studied in the CC (De León Reyes et al., 2020; Innocenti, 2020). They cannot be merely explained by selective repulsion from the cortical plate, although they do not discard its contribution. For instance, we observe that knocking down or overexpressing Nrp1 delays the branching of SSL2/3 callosal axons in the cortical plate of P16 animals. These reductions are similar in all areas and both conditions, thus indicating that axons are not simply following a gradient. Instead, these P16 defects may reflect unbalanced ratios of stabilization/elimination of the synapses of callosal axons with their targets, which would decrease the rate of productive axonal branching and slow, but not block, cortical innervation (Courchet et al., 2013). In agreement, shNrp1 and CAG-Nrp1 $\mathrm{GFP}^{+}$callosal axons had innervated contralateral areas by P30. Competition is also suggested by the reconstitution of the S2 column in P30 shNrp1 IUE brains, which indicates that electroporated S1L2/3 branches outcompete homotopic S2L2/3 projections in these brains (Figure 6B). By contrast, the reduced P30 $\mathrm{GFP}^{+} \mathrm{S} 2$ column in brains overexpressing Nrp1 is accounted for by the shift of all callosal projections towards the more medial S1 (Figure 6C). This is not in disagreement with repulsions, nor with other possible mechanisms. In every case, to dissect the connectivity produced by our manipulations of Nrp1, it is useful to examine why our manipulations alter the development of S2L2/3 callosal projections more than S1L2/3 CPNs. This is likely due to the nature of the endogenous gradient. While overexpressing vectors 
286 maximize the levels of Nrp1 equally in all neurons, the effects of shRNA constructs

287 depend on the endogenous expression of the targeted transcripts and may result in 288 intermediate and low Nrp1 levels in S1L2/3 and S2L2/3 neurons, respectively (Figure 289 6B). Accordingly, shNrp1-targeted S1L2/3 CPNs branching in S2 mimic the behavior of 290 S2L2/3 WT neurons. Unfortunately, we could not assess the levels of Nrp1 protein in 291 targeted electroporated neurons. In our attempts, antibody staining of Nrp1 did not detect 292 the protein in the neuronal somas but only in the midline, similarly to other reports (Piper 293 et al., 2009; Zhao et al., 2011; Zhou et al., 2013; Lim et al., 2015).

294 Hence, the effects of manipulating Nrp1 expression levels agree with that in the canonical 295 WT circuit, interhemispheric axons from S1 neurons, which express higher levels of 296 Nrp1, branch more profusely in homotopic S1 areas. Likewise, those projections from S2 297 CPNs, expressing lower Nrp1 levels, preferentially connect with contralateral homotopic 298 targets in S2 (Figure 6A) (Yorke and Caviness, 1975; Wise and Jones, 1976; De León 299 Reyes et al., 2020). Electroporation of shNrp1 diminished homotopic S2L2/3 projections, 300 which for a fraction of S2L2/3 CPNs, lead to the elimination of their callosal axons. These neurons presumably become ipsilateral-only projecting neurons, as it occurs to WT S1L4 and most other L2/3 cortical neurons during developmental normal refinement (Innocenti and Clarke, 1984; O’Leary and Koester, 1993; De Leon Reyes et al., 2019). Interestingly, the refinement of these CPNs indicates that a certain level of Nrp1 expression is required for terminal callosal innervation. This again that not support axonal repulsion, may suggest a disadvantage at a possible axonal competition.

Sema3A seems a likely candidate responsible for the late branching phenotypes mediated by Nrp1. It has a developmental expression gradient opposite to Nrp1. This complementary expression determines repulsion (Kitsukawa et al., 1997; Zhao et al., 2011; Zhou et al., 2013). In either case, a possible sequential role of Nrp1 in guidance and refinement is in agreement with observations in the cerebellum, where Nrp1 also has a dual function (Telley et al., 2016). First, it guides inhibitory axons to their excitatory neuronal targets, and then, it determines the formation of synapses at specific locations within the neuronal body. The loss of Nrp1 in presynaptic basket cells blocks the formation of axonal synapses with Purkinje neurons, which resembles the inability of 316 those Nrp1 deficient S2L2/3 CPNs to stabilize their callosal projections. In line with the 317 involvement ofNrp1 signaling in refinement, L2/3 PlexinD1 mutant neurons show 
318 abnormal heterotopic callosal projections to the contralateral striatum, possibly due to

319 deregulated developmental refinement (Velona et al., 2019).

320 In sum, we demonstrate that in the somatosensory cortex, Nrp1 regulates the 321 developmental postnatal growth and refinement of L2/3 callosal axons. In this manner, 322 the Nrp1 gradient determines balanced homotopic and heterotopic interhemispheric 323 connectivity between primary and secondary somatosensory circuits. 
bioRxiv preprint doi: https://doi.org/10.1101/2021.05.12.443798; this version posted May 14, 2021. The copyright holder for this preprint (which was not certified by peer review) is the author/funder, who has granted bioRxiv a license to display the preprint in perpetuity. It is made available under aCC-BY-NC-ND 4.0 International license.

Figure 6

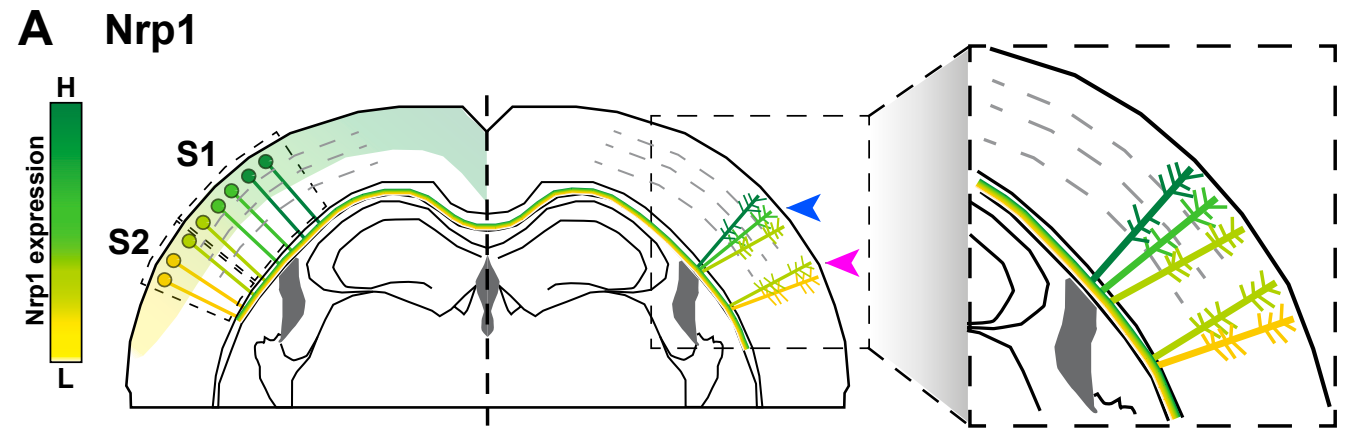

\section{B $\operatorname{shNrp1}$}

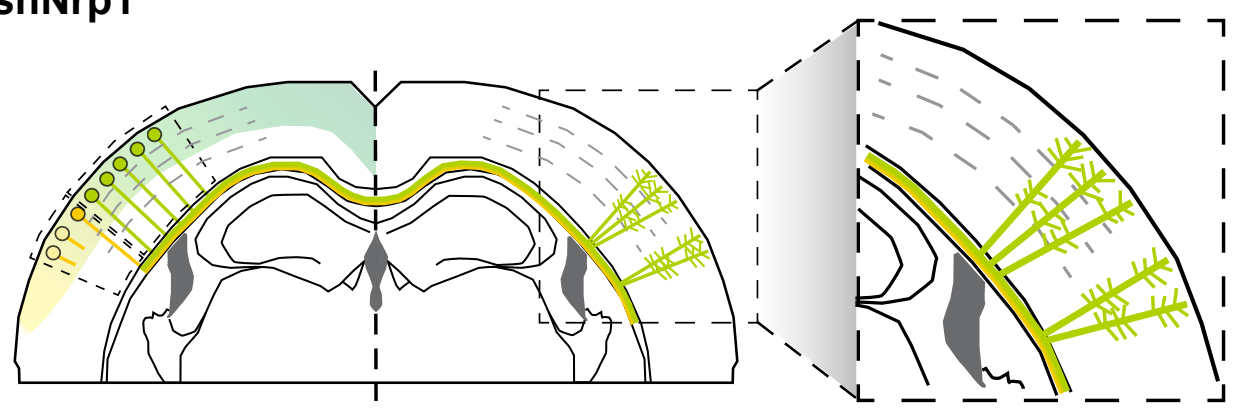

\section{CAG-Nrp1}

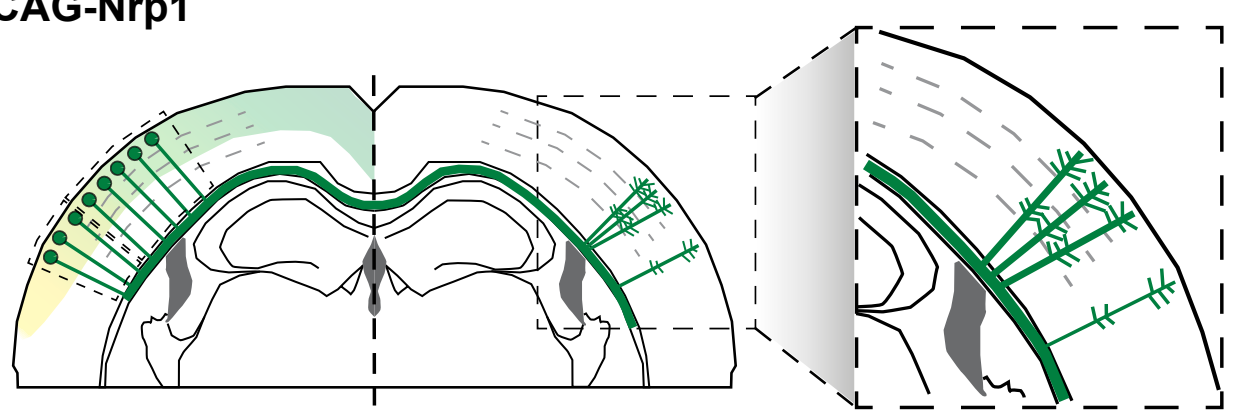

Figure 6. Model of the effects of Nrp1 levels on callosal connectivity. A) Nrp1 is expressed in the cortex in a high-medial, to low-lateral, gradient (higher levels in green, lower levels in yellow). Accordingly, S1L2/3 neurons (green dots) express high to intermediate levels of Nrp1. S2L2/3 neurons express low levels (light green and yellow dots). L2/3 neurons expressing high to intermediate levels of Nrp1 branch preferentially in homotopic S1/S2 column (blue arrow), and S2L2/3 neurons expressing intermediate to low levels into S2 areas (magenta arrow). B) Knocking down Nrp1 reduces the levels of Nrp1 according to the gradient. L2/3 CPNs with intermediate levels of Nrp1 expression can branch both in S1/S2 and S2. As consequence, an exceeding number of heterotopic branches from S1L2/3 CPNs outgrowth ectopically in the S2 column. They may outcompete axons of shNrp1 targeted S2L2/3 neurons that express very low levels of Nrp1 (light yellow dots). Many of these S2L2/3 neurons cannot terminate innervation and refine their callosal axon during the late period of P16-P30 developmental CPN refinement, thus becoming ipsilateral-only connecting neurons. C) Neurons over-expressing Nrp1 branch in the $\mathrm{S} 1 / \mathrm{S} 2$ column but are not competent to innervate $\mathrm{S} 2$ areas, which is then significantly reduced. 


\section{Animals}

Wild-type (WT) C57BL6JRccHsd (Envigo Laboratories, formerly Harlan. Indianapolis, the U.S.) mice were used in all experiments. The morning of the day of the appearance of a vaginal plug was defined as embryonic day 0.5 (E 0.5). Animals were housed and maintained following the guidelines from the European Union Council Directive

330 (86/609/European Economic Community). All procedures for handling and sacrificing complied with all relevant ethical regulations for animal testing and research. All experiments were performed under the European Commission guidelines (2010/63/EU) and were approved by the CSIC and the Community of Madrid Ethics Committees on Animal Experimentation in compliance with national and European legislation (PROEX $124-17 ; 123-17)$.

\section{In utero electroporation and plasmids}

337 Plasmids used were pCAG-GFP (Addgene, plasmid \#11150), pCAG-Nrp1 (gift from 338 Prof. Mu-ming Poo), and shNrpl in pLKO.1 vector (hairpin sequence: 339 CCTGCTTTCTTCTCTTGGTTTC. \#TRCN0000029859, Merck. Darmstadt. Germany). 340 In utero electroporation was performed as previously described (Briz et al., 2017).

341 Briefly, a mixture of the specified plasmids at a concentration of $1 \mu \mathrm{g} / \mu \mathrm{l}$ each (pCAG342 GFP or pCAG-Nrp1) or $0.6 \mu \mathrm{g} / \mu \mathrm{l}$ (pLKO.1-shNrp1) was injected into the embryo's left 343 lateral ventricle using pulled glass micropipette. Five voltage pulses $(38 \mathrm{mv}, 50 \mathrm{~ms})$ were 344 applied using external paddles oriented to target the somatosensory cortex. After birth, $345 \mathrm{P} 2 \mathrm{GFP}^{+}$pups were selected and allowed to develop normally until P14 and P28. After 346 sectioning, analyses were performed only in animals in which the electroporated area included both $\mathrm{S} 1$ and $\mathrm{S} 2$.

\section{CTB injections for retrograde labeling}

349 Retrograde labeling from the $\mathrm{CC}$ and the cortical plate were performed by injecting 350 subunit B of cholera toxin (CTB) conjugated to Alexa Fluor 555 (\#C-34776, 351 ThermoFisher Scientific. Massachusetts, the U.S.). Injections were performed in the CC, 352 close to the midline, as previously reported (De Leon Reyes et al., 2019), or in the cortical 353 plate; in both cases, in the contralateral non-electroporated hemisphere (right hemisphere). Stereotaxic coordinates, injection volumes, and procedures for different 
355 developmental stages for injections in CC were performed as previously described (De

356 Leon Reyes et al., 2019). For cortical plate injections at P30, stereotaxic coordinates

357 (anteroposterior (AP), mediolateral (ML), and dorsoventral (DV) axes from Bregma)

358 were adjusted using the atlas of Paxinos (Paxinos and Franklin, 2004) and used as follow:

$359 \mathrm{~S} 1 / \mathrm{S} 2$ injections (-1.34 mm AP; +3.7 mm ML; -0.4 -0.5 mm DV) and, S2 injections (-

$3601.34 \mathrm{~mm} \mathrm{AP} ;+3,7 \mathrm{~mm} \mathrm{ML} ;-0.7 \sim-0.8 \mathrm{~mm} \mathrm{DV})$; injecting $100 \mathrm{~nL}$ of CTB solution at 4

$361 \mathrm{nl} \mathrm{s}^{-1}$. Animals were anesthetized during the surgical procedure with isoflurane/oxygen

362 and placed on a stereotaxic apparatus (Harvard Apparatus. Massachusetts, the U.S.). CTB

363 particles (diluted at $0.5 \%$ in phosphate-buffered saline (PBS)) were injected with a

364 Drummond Nanoject II Auto-Nanoliter Injector using $30 \mathrm{~mm}$ pulled glass micropipettes

365 (3000205A and 3000203G/X. Drummond Scientific Co. Pennsylvania, the U.S.). Mice

366 were intrapericardially perfused with formalin two days after the surgery and brains were

367 extracted and fixed overnight in formalin at $4^{\circ} \mathrm{C}$. After fixation, brains were cryoprotected

368 with 30\% sucrose (\#S0389. Merck. Darmstadt. Germany) and frozen in Tissue-Tek ${ }^{\circledR}$

369 O.C.T. ${ }^{\text {TM }}$ Compound (\#4583, Sakura Tissue-Tek. Tokyo. Japan).

\section{$370 \quad$ Immunohistochemistry}

$37150 \mu \mathrm{m}$ free-floating brain cryosections were used for immunofluorescence. Rabbit 372 polyclonal anti-GFP (\#A11122, Thermo Fisher Scientific. Invitrogen. Massachusetts, the 373 U.S.) was used as primary antibody and goat anti-rabbit-Alexa 488 (\#A11034, Thermo 374 Fisher Scientific. Life Technologies. Massachusetts, the U.S.) as the secondary antibody. 375 Nuclei were stained with 4',6-diamidino-2-phenylindole (DAPI) (\#D9542, Merck. 376 Darmstadt. Germany).

\section{Confocal imaging and quantification}

378 Confocal microscopy was performed using a TCS-SP5 (Leica. Wetzlar. Germany) Laser 379 Scanning System on Leica DMI8 microscopes. Up to $50 \mu \mathrm{m}$ optical z-sections were 380 obtained by taking $3.5 \mu \mathrm{m}$ serial sections with LAS AF v1.8 software (Leica. Wetzlar. 381 Germany). Tilescan mosaic images were reconstructed with Leica LAS AF software. All 382 images were acquired using a 512 x 512 scan format with a $20 x$ objective.

383 For the acquisition and quantifications of the fluorescence signal (Rodriguez-Tornos et al., 2016; Briz et al., 2017), detectors were set to ensure equivalent threshold and signalto-noise ratios between all samples. The maximum threshold signal was set by ensuring that no pixels were saturated. The threshold for background noise was determined using 
387 regions outside of the electroporated area (Rodriguez-Tornos et al., 2016; Briz et al., 388 2017). This approach ensures linearity between samples. Quantification of innervation 389 was performed in tilescan images of electroporated (ipsilateral) and non-electroporated 390 (contralateral) hemispheres. Different areas were measured delimitating manually ROIs,

391 adjusting the threshold above the noise (making a binary image), and measuring the 392 integrated density (using Fiji-ImageJ (Schindelin et al., 2012)). Measures of contralateral 393 ROIs were normalized to ipsilateral ones to avoid any differences in electroporation 394 efficiency. Contralateral normalizations, without considering ipsilateral signal, were calculated to confirm the results. To quantify $\mathrm{CC}$ fasciculation, a midline ROI was selected to measure the fluorescence profile throughout ten equal distance bins. The different profiles were plotted to identify changes in dorsoventral routes.

Quantification of $\mathrm{CTB}^{+}$over $\mathrm{GFP}^{+}$cells in the primary (S1) and secondary (S2) somatosensory areas was performed on single plane confocal images from z-stacks (De

400 Leon Reyes et al., 2019). The proportions of $\mathrm{CTB}^{+}$cells were calculated among randomly 401 selected $\mathrm{GFP}^{+}$cells in the ipsilateral (electroporated) hemisphere. For quantification of $402 \mathrm{GFP}^{-}$populations, the proportions of $\mathrm{CTB}^{+}$cells were calculated over randomly selected $403 \mathrm{DAPI}^{+}$cells, excluding $\mathrm{GFP}^{+}$cells. Functional areas of the adult mouse brain were identified using the atlas of Paxinos (Paxinos and Franklin, 2004).

\section{Statistical analysis}

406 Sample size was determined to be adequate based on the magnitude and consistency of 407 measurable differences between groups. Each experimental condition was carried out 408 with a minimum of three biological replicates, a minimum of two sections from each 409 brain, and included a minimum total number of 300 counted cells. During experiments, 410 investigators were not blinded to the electroporation condition of animals. Results are 411 expressed as the mean \pm standard error of the mean (SEM). Results were compared using 412 two-way ANOVA and one-way ANOVA with posthoc comparison with Tukey and 413 Bonferroni's tests. Statistical tests were performed using Prism 8 software (GraphPad 414 Software. California, the U.S.). 


\section{Article and author information}

416 Author details:

\section{F. Martín-Fernández}

418 National Center of Biotechnology. Consejo Superior de Investigaciones Científicas.

419 CNB-CSIC. Spain.

420 Contribution: conceptualization, formal analysis, validation, investigation, visualization,

421 methodology, writing.

422 C. García-Briz

423 National Center of Biotechnology. Consejo Superior de Investigaciones Científicas.

424 CNB-CSIC. Spain. Present address: Ministry of Consumer Affairs. Spain Govern.

425 Contribution: conceptualization, investigation, methodology.

\section{M. Nieto}

427 National Center of Biotechnology. Consejo Superior de Investigaciones Científicas.

428 CNB-CSIC. Spain.

429 Contribution: conceptualization, writing.

430 Acknowledgments

431 We are grateful to R. Gutierrez, A. Morales, S. Gutiérrez-Erlandsson, and A. Oña for 432 technical assistance. J. García-Marqués, L.A. Weiss, N. S. de León, I. Varela, E. Marcos, 433 and L. Bragg for critical reading and advice. F. Martín-Fernández holds an FPU 434 fellowship from the Spanish MEFP, FPU15/02111. C. García-Briz was supported by a 435 fellowship from the Spanish MICINN, FPI-BES-2012-056011. This work was funded by 436 grants from the Ministerio de Ciencia, Innovación y Universidades/Agencia Estatal de 437 Investigación/Fondo Europeo de Desarrollo Regional, European Union (SAF2017438 83117-R and RED2018-102553T).

\section{Competing Interests}

440 The authors declare no competing interests. 


\section{References}

442

443

444

445

446

447

448

449

450
Aboitiz, F. and Montiel, J. (2003) "One hundred million years of interhemispheric communication: the history of the corpus callosum", Braz J Med Biol Res, 36(4), pp. 409-20. doi:10.1590/s0100-879x2003000400002.

Antón-Bolaños, N., Sempere-Ferràndez, A., Guillamón-Vivancos, T., Martini, F. J., Pérez-Saiz, L., Gezelius, H., Filipchuk, A., Valdeolmillos, M. and López-Bendito, G. (2019) "Prenatal activity from thalamic neurons governs the emergence of functional cortical maps in mice", Science, 364(6444), pp. 987-990. doi:10.1126/science.aav7617.

Briz, C. G., Navarrete, M., Esteban, J. A. and Nieto, M. (2017) "In Utero Electroporation Approaches to Study the Excitability of Neuronal Subpopulations and Single-cell Connectivity", J Vis Exp, (120). doi:10.3791/55139.

Courchet, J., Lewis, T. L., Lee, S., Courchet, V., Liou, D.-Y., Aizawa, S. and Polleux, F. (2013) "Terminal Axon Branching Is Regulated by the LKB1-NUAK1 Kinase Pathway via Presynaptic Mitochondrial Capture", Cell, 153(7), pp. 1510-1525. doi:10.1016/j.cell.2013.05.021.

De León Reyes, N. S., Bragg-Gonzalo, L. and Nieto, M. (2020) "Development and plasticity of the corpus callosum", Development (Cambridge, England), 147(18). doi:10.1242/dev.189738.

De Leon Reyes, N. S., Mederos, S., Varela, I., Weiss, L. A., Perea, G., Galazo, M. J. and Nieto, M. (2019) "Transient callosal projections of L4 neurons are eliminated for the acquisition of local connectivity", Nat Commun, 10(1), p. 4549. doi:10.1038/s41467-019-12495-w.

Dehay, C., Kennedy, H. and Bullier, J. (1986) "Callosal connectivity of areas V1 and V2 in the newborn monkey", The Journal of Comparative Neurology, 254(1), pp. 2033. doi:10.1002/cne.902540103.

Fame, R. M., MacDonald, J. L. and Macklis, J. D. (2011) "Development, specification, and diversity of callosal projection neurons", Trends Neurosci, 34(1), pp. 41-50. doi:10.1016/j.tins.2010.10.002.

Fenlon, L. R. and Richards, L. J. (2015) "Contralateral targeting of the corpus callosum in normal and pathological brain function", Trends Neurosci, 38(5), pp. 264-72. doi:10.1016/j.tins.2015.02.007.

Fenlon, L. R., Suárez, R. and Richards, L. J. (2017) "The anatomy, organisation and development of contralateral callosal projections of the mouse somatosensory cortex", Brain and Neuroscience Advances, 1, p. 239821281769488. doi:10.1177/2398212817694888.

Fournier, A. E., Nakamura, F., Kawamoto, S., Goshima, Y., Kalb, R. G. and Strittmatter, S. M. (2000) "Semaphorin3A enhances endocytosis at sites of receptor-Factin colocalization during growth cone collapse", J Cell Biol, 149(2), pp. 411-22. doi:10.1083/jcb.149.2.411. 
480 Gu, C., Rodriguez, E. R., Reimert, D. V., Shu, T., Fritzsch, B., Richards, L. J.,

481 Kolodkin, A. L. and Ginty, D. D. (2003) "Neuropilin-1 conveys semaphorin and VEGF

482 signaling during neural and cardiovascular development", Dev Cell, 5(1), pp. 45-57.

483 doi:10.1016/s1534-5807(03)00169-2.

484 Hatanaka, Y., Matsumoto, T., Yanagawa, Y., Fujisawa, H., Murakami, F. and Masu, M. 485 (2009) "Distinct roles of neuropilin 1 signaling for radial and tangential extension of 486 callosal axons", J Comp Neurol, 514(3), pp. 215-25. doi:10.1002/cne.22021.

487 Hill, R. S. and Walsh, C. A. (2005) "Molecular insights into human brain evolution", 488 Nature, 437(7055), pp. 64-7. doi:10.1038/nature04103.

489 Huang, Y., Song, N.-N., Lan, W., Zhang, Q., Zhang, Ling, Zhang, Lei, Hu, L., Chen, J.490 Y., Zhao, C.-J., Li, L., Xu, L. and Ding, Y.-Q. (2013) "Sensory input is required for 491 callosal axon targeting in the somatosensory cortex", Molecular Brain, 6, p. 53.

492 doi:10.1186/1756-6606-6-53.

493 Inan, M. and Crair, M. C. (2007) "Development of cortical maps: perspectives from the barrel cortex", The Neuroscientist: A Review Journal Bringing Neurobiology, Neurology and Psychiatry, 13(1), pp. 49-61. doi:10.1177/1073858406296257.

Innocenti, G. M. (2020) "The Target of Exuberant Projections in Development", Cerebral Cortex, 30(6), pp. 3820-3826. doi:10.1093/cercor/bhz344. connections", J Comp Neurol, 230(2), pp. 287-309. doi:10.1002/cne.902300212.

500 Innocenti, G. M. and Price, D. J. (2005) "Exuberance in the development of cortical networks", Nature Reviews Neuroscience, 6(12), pp. 955-965. doi:10.1038/nrn1790.

Kitsukawa, T., Shimizu, M., Sanbo, M., Hirata, T., Taniguchi, M., Bekku, Y., Yagi, T. and Fujisawa, H. (1997) "Neuropilin-semaphorin III/D-mediated chemorepulsive signals play a crucial role in peripheral nerve projection in mice", Neuron, 19(5), pp. 995-1005. doi:10.1016/s0896-6273(00)80392-x.

Koralek, K. A. and Killackey, H. P. (1990) "Callosal projections in rat somatosensory 507 cortex are altered by early removal of afferent input.", Proceedings of the National 508 Academy of Sciences. National Academy of Sciences, 87(4), pp. 1396-1400. 509 doi:10.1073/pnas.87.4.1396.

510 Lim, J. W. C., Donahoo, A.-L. S., Bunt, J., Edwards, T. J., Fenlon, L. R., Liu, Y., Zhou, 511 J., Moldrich, R. X., Piper, M., Gobius, I., Bailey, T. L., Wray, N. R., Kessaris, N., Poo, 512 M.-M., Rubenstein, J. L. R. and Richards, L. J. (2015) "EMX1 regulates NRP1513 mediated wiring of the mouse anterior cingulate cortex", Development (Cambridge, 514 England), 142(21), pp. 3746-3757. doi:10.1242/dev.119909.

515 Meissirel, C., Dehay, C., Berland, M. and Kennedy, H. (1991) "Segregation of callosal 516 and association pathways during development in the visual cortex of the primate", The 517 Journal of Neuroscience, 11(11), pp. 3297-3316. doi:10.1523/JNEUROSCI.11-1151803297.1991. 
519 Miller, M. W. and Vogt, B. A. (1984) "Heterotopic and homotopic callosal connections

520 in rat visual cortex", Brain Research, 297(1), pp. 75-89. doi:10.1016/0006-

521 8993(84)90544-4.

522 Mire, E., Hocine, M., Bazellières, E., Jungas, T., Davy, A., Chauvet, S. and Mann, F. 523 (2018) "Developmental Upregulation of Ephrin-B1 Silences Sema3C/Neuropilin-1 524 Signaling during Post-crossing Navigation of Corpus Callosum Axons", Current 525 biology: $C B, 28(11)$, pp. 1768-1782.e4. doi:10.1016/j.cub.2018.04.026.

Mitchell, B. D. and Macklis, J. D. (2005) "Large-scale maintenance of dual projections by callosal and frontal cortical projection neurons in adult mice", J Comp Neurol, 528 482(1), pp. 17-32. doi:10.1002/cne.20428.

Mizuno, H., Hirano, T. and Tagawa, Y. (2007) "Evidence for Activity-Dependent Cortical Wiring: Formation of Interhemispheric Connections in Neonatal Mouse Visual Cortex Requires Projection Neuron Activity", Journal of Neuroscience. Society for Neuroscience, 27(25), pp. 6760-6770. doi:10.1523/JNEUROSCI.1215-07.2007.

Muche, A., Bigl, M., Arendt, T. and Schliebs, R. (2015) "Expression of vascular endothelial growth factor (VEGF) mRNA, VEGF receptor 2 (Flk-1) mRNA, and of VEGF co-receptor neuropilin (Nrp)-1 mRNA in brain tissue of aging Tg2576 mice by in situ hybridization", International Journal of Developmental Neuroscience, 43(1), pp. 25-34. doi:https://doi.org/10.1016/j.ijdevneu.2015.03.003.

Niquille, M., Garel, S., Mann, F., Hornung, J. P., Otsmane, B., Chevalley, S., Parras, C., 539 Guillemot, F., Gaspar, P., Yanagawa, Y. and Lebrand, C. (2009) "Transient neuronal 540 populations are required to guide callosal axons: a role for semaphorin 3C", PLoS Biol, 541 7(10), p. e1000230. doi:10.1371/journal.pbio.1000230.

O'Leary, D. D. M. (1992) "Development of connectional diversity and specificity in the mammalian brain by the pruning of collateral projections", Current Opinion in Neurobiology, 2(1), pp. 70-77. doi:10.1016/0959-4388(92)90165-H.

O’Leary, D. D. M. and Koester, S. E. (1993) "Development of projection neuron types, axon pathways, and patterned connections of the mammalian cortex", Neuron, 10(6), pp. 991-1006. doi:10.1016/0896-6273(93)90049-W.

Paxinos, G. and Franklin, K. B. J. (2004) The mouse brain in stereotaxic coordinates (1 vol). Compact 2nd. Amsterdam; Boston: Elsevier Academic Press.

Piper, M., Plachez, C., Zalucki, O., Fothergill, T., Goudreau, G., Erzurumlu, R., Gu, C. and Richards, L. J. (2009) "Neuropilin 1-Sema signaling regulates crossing of cingulate pioneering axons during development of the corpus callosum", Cereb Cortex, 19 Suppl 1, pp. i11-21. doi:10.1093/cercor/bhp027. and Jabaudon, D. (2014) "Modality-specific thalamocortical inputs instruct the identity of postsynaptic L4 neurons", Nature, 511(7510), pp. 471-474. doi:10.1038/nature13390. 
560 Rodriguez-Tornos, F. M., Briz, C. G., Weiss, L. A., Sebastian-Serrano, A., Ares, S.,

561 Navarrete, M., Frangeul, L., Galazo, M., Jabaudon, D., Esteban, J. A. and Nieto, M.

562 (2016) "Cux1 Enables Interhemispheric Connections of Layer II/III Neurons by

563 Regulating Kv1-Dependent Firing", Neuron, 89(3), pp. 494-506.

564 doi:10.1016/j.neuron.2015.12.020.

565 Schindelin, J., Arganda-Carreras, I., Frise, E., Kaynig, V., Longair, M., Pietzsch, T.,

566 Preibisch, S., Rueden, C., Saalfeld, S., Schmid, B., Tinevez, J.-Y., White, D. J.,

567 Hartenstein, V., Eliceiri, K., Tomancak, P. and Cardona, A. (2012) "Fiji: an open-source

568 platform for biological-image analysis", Nature Methods, 9(7), pp. 676-682.

569 doi:10.1038/nmeth.2019.

570 Stanfield, B. B., O’Leary, D. D. M. and Fricks, C. (1982) "Selective collateral elimination in early postnatal development restricts cortical distribution of rat pyramidal tract neurones", Nature, 298(5872), pp. 371-373. doi:10.1038/298371a0.

Suárez, R., Fenlon, L. R., Marek, R., Avitan, L., Sah, P., Goodhill, G. J. and Richards, L. J. (2014) "Balanced interhemispheric cortical activity is required for correct targeting of the corpus callosum", Neuron, 82(6), pp. 1289-1298.

576 doi:10.1016/j.neuron.2014.04.040.

577 Suarez, R., Gobius, I. and Richards, L. J. (2014) "Evolution and development of 578 interhemispheric connections in the vertebrate forebrain", Front Hum Neurosci, 8, p. 579 497. doi:10.3389/fnhum.2014.00497.

580 Takahashi, T., Fournier, A., Nakamura, F., Wang, L. H., Murakami, Y., Kalb, R. G., 581 Fujisawa, H. and Strittmatter, S. M. (1999) "Plexin-neuropilin-1 complexes form 582 functional semaphorin-3A receptors", Cell, 99(1), pp. 59-69. doi:10.1016/s0092583 8674(00)80062-8.

Tamamaki, N., Fujimori, K., Nojyo, Y., Kaneko, T. and Takauji, R. (2003) "Evidence that Sema3A and Sema3F regulate the migration of GABAergic neurons in the developing neocortex", Journal of Comparative Neurology, 455(2), pp. 238-248. doi:https://doi.org/10.1002/cne.10476.

Telley, L., Cadilhac, C., Cioni, J.-M., Saywell, V., Jahannault-Talignani, C., Huettl, R. E., Sarrailh-Faivre, C., Dayer, A., Huber, A. B. and Ango, F. (2016) "Dual Function of NRP1 in Axon Guidance and Subcellular Target Recognition in Cerebellum", Neuron, 91(6), pp. 1276-1291. doi:10.1016/j.neuron.2016.08.015.

Velona, T., Altounian, M., Roque, M., Hocine, M., Bellon, A., Briz, C. G., Salin, P., Nieto, M., Chauvet, S. and Mann, F. (2019) "PlexinD1 and Sema3E determine laminar positioning of heterotopically projecting callosal neurons", Molecular and Cellular 595 Neuroscience, 100, p. 103397. doi:10.1016/j.mcn.2019.103397.

596 Watson, C. (2012) "Chapter 21 - The Somatosensory System", in Watson, C., Paxinos, 597 G., and Puelles, L. (eds.) The Mouse Nervous System. San Diego: Academic Press, pp. $598 \quad 563-570$.

599 Wise, S. P. and Jones, E. G. (1976) "The organization and postnatal development of the 600 commissural projection of the rat somatic sensory cortex", J Comp Neurol, 168(3), pp.

601 313-43. doi:10.1002/cne.901680302. 
602 Wu, K. Y., He, M., Hou, Q. Q., Sheng, A. L., Yuan, L., Liu, F., Liu, W. W., Li, G.,

603 Jiang, X. Y. and Luo, Z. G. (2014) "Semaphorin 3A activates the guanosine

604 triphosphatase Rab5 to promote growth cone collapse and organize callosal axon

605 projections", Sci Signal, 7(340), p. ra81. doi:10.1126/scisignal.2005334.

606 Yorke, C. H. and Caviness, V. S. (1975) "Interhemispheric neocortical connections of

607 the corpus callosum in the normal mouse: a study based on anterograde and retrograde

608 methods", J Comp Neurol, 164(2), pp. 233-45. doi:10.1002/cne.901640206.

609 Zhao, H., Maruyama, T., Hattori, Y., Sugo, N., Takamatsu, H., Kumanogoh, A.,

610 Shirasaki, R. and Yamamoto, N. (2011) "A molecular mechanism that regulates

611 medially oriented axonal growth of upper layer neurons in the developing neocortex", $J$

612 Comp Neurol, 519(5), pp. 834-48. doi:10.1002/cne.22536.

613 Zhou, J., Wen, Y., She, L., Sui, Y. N., Liu, L., Richards, L. J. and Poo, M. M. (2013)

614 "Axon position within the corpus callosum determines contralateral cortical projection", 615 Proc Natl Acad Sci US A, 110(29), pp. E2714-23. doi:10.1073/pnas.1310233110. 
bioRxiv preprint doi: https://doi.org/10.1101/2021.05.12.443798; this version posted May 14, 2021. The copyright holder for this preprint (which was not certified by peer review) is the author/funder, who has granted bioRxiv a license to display the preprint in perpetuity. It is made available under aCC-BY-NC-ND 4.0 International license.

\section{Figure 1 - figure supplement 1}

A

$\mathrm{S} 2$ column relative to $\mathrm{S} 1 / \mathrm{S} 2$ column $(\mathrm{P} 30)$
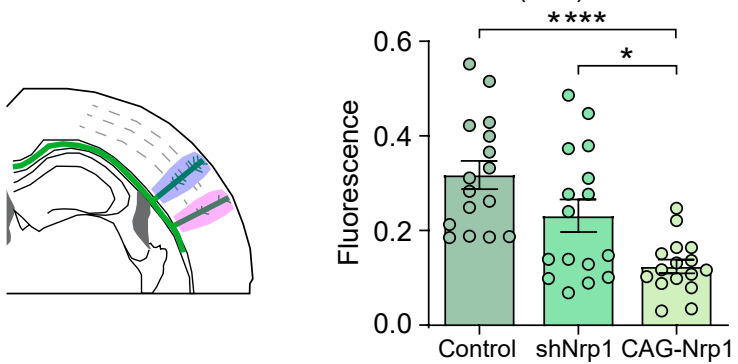

B

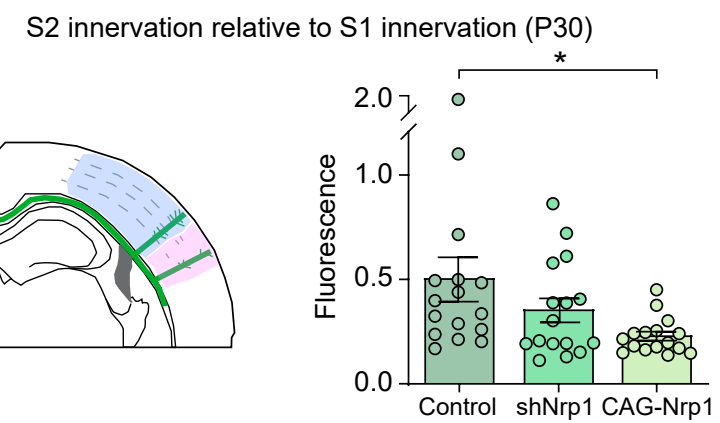

Figure 1 - figure supplement 1. Analysis of contralateral innervation of SS cortex at P30 upon Nrp1 modifications. A-B) Quantification of axonal distribution in the contralateral hemisphere. The left panels depict schemes showing the selected ROIs in which $\mathrm{GFP}^{+}$is quantified (shaded areas). Graphs show values of relative contralateral GFP innervation. Mean \pm SEM ( $n=8$ brains, 2 sections per brain, in all conditions). A) S2 column relative to $\mathrm{S} 1 / \mathrm{S} 2$ column (One-way ANOVA: $P$-value $<0.0001$. Post-hoc with Tukey's test: $* * * *$-value control-CAG-Nrp1 $<0.0001 ; * p$-value shNrp1 CAG-Nrp1 $=0.0231)$. B) S2 innervation relative to $\mathrm{S} 1$ innervation (One-way ANOVA: $P$-value $=0.0329$ Posthoc with Tukey's test: * $p$-value control-CAG-Nrp1 $=0.0252$ ). 
bioRxiv preprint doi: https://doi.org/10.1101/2021.05.12.443798; this version posted May 14, 2021. The copyright holder for this preprint (which was not certified by peer review) is the author/funder, who has granted bioRxiv a license to display the preprint in perpetuity. It is made available under aCC-BY-NC-ND 4.0 International license.

\section{Figure 1 - figure supplement 2}
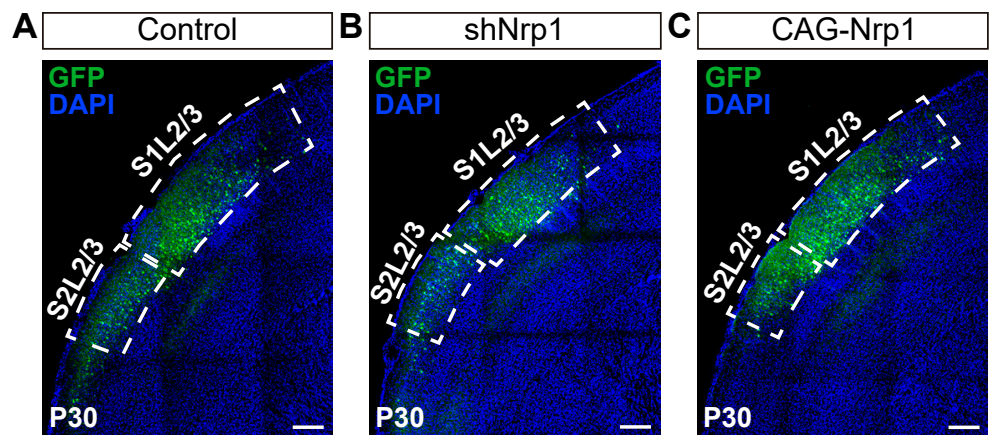

D Percentage of $\mathrm{GFP}^{+}$neurons in $\mathrm{S} 1 \mathrm{~L} 2 / 3$

E Percentage of $\mathrm{GFP}^{+}$neurons in
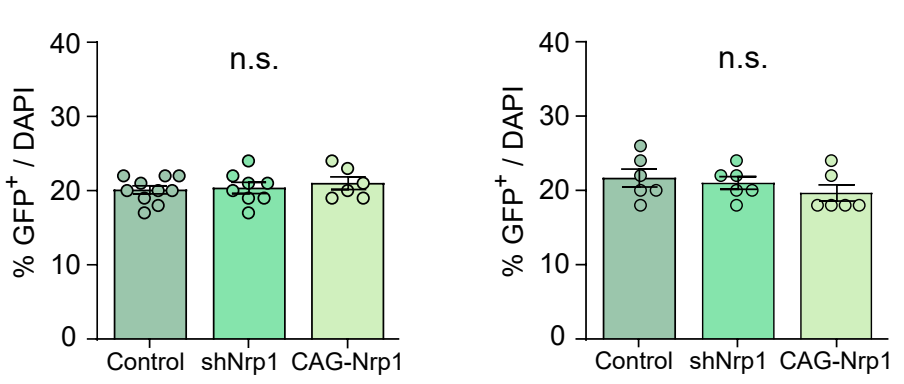

Figure 1 - figure supplement 2. Analysis of proportions of GFP $^{+}$electroporated neurons in the ipsilateral side in somatosensory areas. A-C) Detail of the ipsilateral hemisphere of P30 electroporated brains from all conditions (Dashed boxes: S1L2/3 electroporated area and S2L2/3 electroporated area). Scale bar $=300 \mu \mathrm{m}$. D-E) Percentage of $\mathrm{GFP}^{+}$neurons over cells $\left(\mathrm{DAPI}^{+}\right)$in $\mathrm{S} 1 \mathrm{~L} 2 / 3$ and $\mathrm{S} 2 \mathrm{~L} 2 / 3$. Mean $\pm \mathrm{SEM}(\mathrm{n} \geq 3$ brains, 2 sections per brain in all conditions). D) S1 area (One-way ANOVA: $P$-value $=0.6769$ (n.s.)). E) S2 area (One-way ANOVA: $P$-value $=0.4172$ (n.s.)). 
bioRxiv preprint doi: https://doi.org/10.1101/2021.05.12.443798; this version posted May 14, 2021. The copyright holder for this preprint (which was not certified by peer review) is the author/funder, who has granted bioRxiv a license to display the preprint in perpetuity. It is made available under aCC-BY-NC-ND 4.0 International license.

Figure 2 - figure supplement 1

A

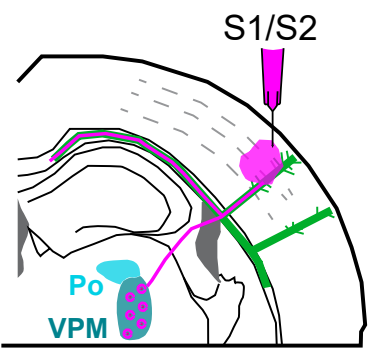

D

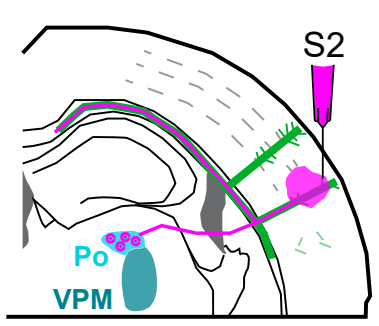

B

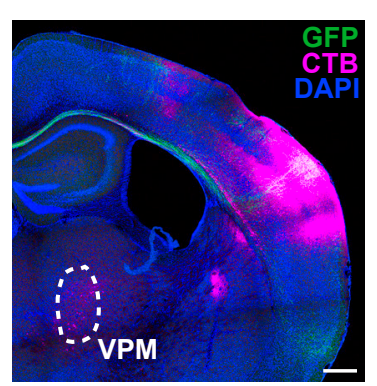

E

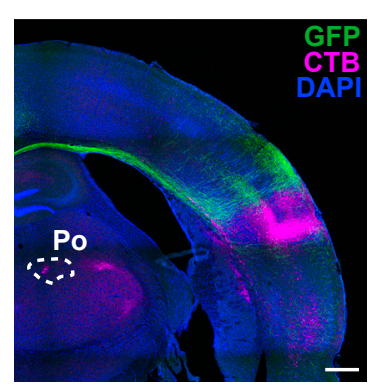

C

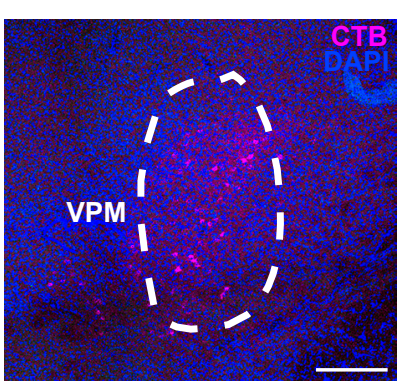

$\mathbf{F}$

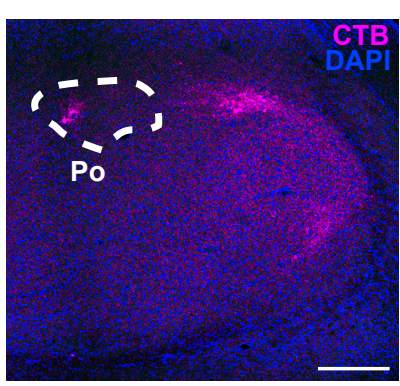

Figure 2 - figure supplement 1. Retrospective control of correct columnar stereotaxic injections. A) Scheme of coronal section of P30 injected brain in S1/S2 column. Thalamus nucleus VPM (ventral posterio medial nuclei) extend thalamocortical axons to S1/S2 column. B) Merge image of coronal section of the contralateral injected side of S1/S2 injection. Dashed line marks VPM, where thalamic neurons are $\mathrm{CTB}^{+}$. Green $=$GFP, Magenta $=\mathrm{CTB}$, Blue $=$ DAPI. Scale bar $=500 \mu \mathrm{m}$. C) Detail of VPM nucleus. Magenta $=\mathrm{CTB}$, Blue $=$ DAPI. Scale bar $=200 \mu \mathrm{m}$. D) Scheme of coronal section of P30 injected brain in S2 column. Thalamus nucleus Po (posterior nucleus) extend thalamocortical axons to the S2 column. E) Merge image of coronal section of contralateral injected side of S2 injection. Dashed line marks Po, where thalamic neurons are $\mathrm{CTB}^{+}$. Green $=$GFP, Magenta $=\mathrm{CTB}$, Blue $=$ DAPI. Scale bar $=500 \mu \mathrm{m} . \mathbf{F}$ ) Detail of Po nucleus. Magenta $=$ CTB, Blue $=$ DAPI. Scale bar $=200 \mu \mathrm{m}$. 
bioRxiv preprint doi: https://doi.org/10.1101/2021.05.12.443798; this version posted May 14, 2021. The copyright holder for this preprint (which was not certified by peer review) is the author/funder, who has granted bioRxiv a license to display the preprint in perpetuity. It is made available under aCC-BY-NC-ND 4.0 International license.

\section{Figure 2 - figure supplement 2}

A
GFP GF $^{+}$
CTBB
- $\mathrm{GFP}^{+} \mathrm{CTB}^{+}$

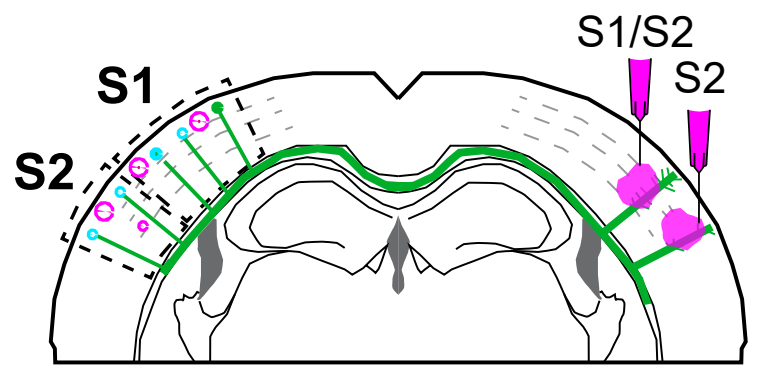

B Location of CPNs from injections in $\mathrm{S} 1 / \mathrm{S} 2$ column

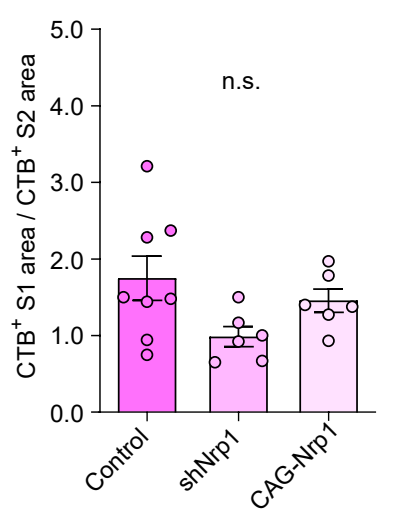

C Location of CPNs from injections in $\mathrm{S} 2$ column

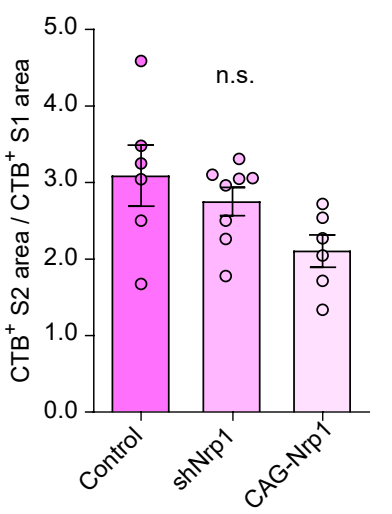

Figure 2 - figure supplement 2. Analysis of location of CPNs neurons at P30 in somatosensory cortex. A) Scheme of coronal section of electroporated and injected brain at P30. The injections were made in S1/S2 column in one group and in S2 column in the other group. $\mathrm{CTB}^{+}$and $\mathrm{GFP}^{+} \mathrm{CTB}^{+}$populations were quantified individually between the $\mathrm{S} 1$ and $\mathrm{S} 2$ area and, in the two types of injections. B-C) Location of $\mathrm{CTB}^{+} \mathrm{CPNs}$ from injections in $\mathrm{S} 1 / \mathrm{S} 2$ column and $\mathrm{S} 2$ column. For $\mathrm{S} 1 / \mathrm{S} 2$ injections, ratio was calculated between $\mathrm{S}_{1} \mathrm{CTB}^{+}$and $\mathrm{S}_{2} \mathrm{CTB}^{+}$neurons. For $\mathrm{S} 2$ injections, ratio was calculated between $\mathrm{S}_{2} \mathrm{CTB}^{+}$ and $\mathrm{S} 1 C T B^{+}$neurons. Mean $\pm \mathrm{SEM}$ ( $\mathrm{n} \geq 3$ brains, 2 sections per brain in all conditions. B) $\mathrm{S} 1 / \mathrm{S} 2$ injections (One-way ANOVA: $P$-value $=0.0840$ (n.s.)). C) S2 injections (One-way ANOVA: $P$-value $=0.0669$ (n.s.)). 
bioRxiv preprint doi: https://doi.org/10.1101/2021.05.12.443798; this version posted May 14, 2021. The copyright holder for this preprint (which was not certified by peer review) is the author/funder, who has granted bioRxiv a license to display the preprint in perpetuity. It is made available under aCC-BY-NC-ND 4.0 International license.

\section{Figure 3 - figure supplement 1}

A

$\mathrm{S} 2$ innervation relative to $\mathrm{S} 1$ innervation (P16)
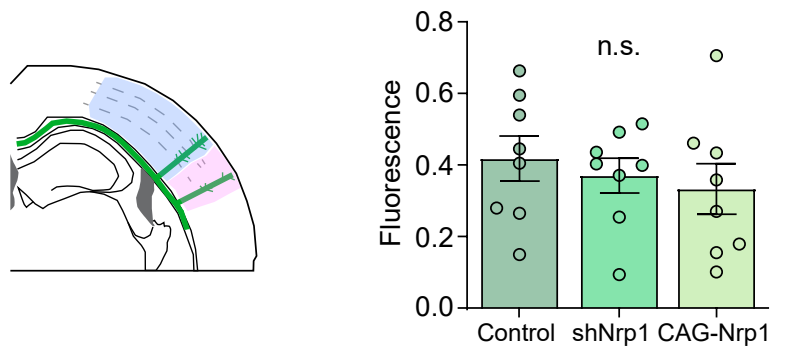

B

$\mathrm{S} 1$ area relative to ipsilateral somas $(\mathrm{P} 16)$
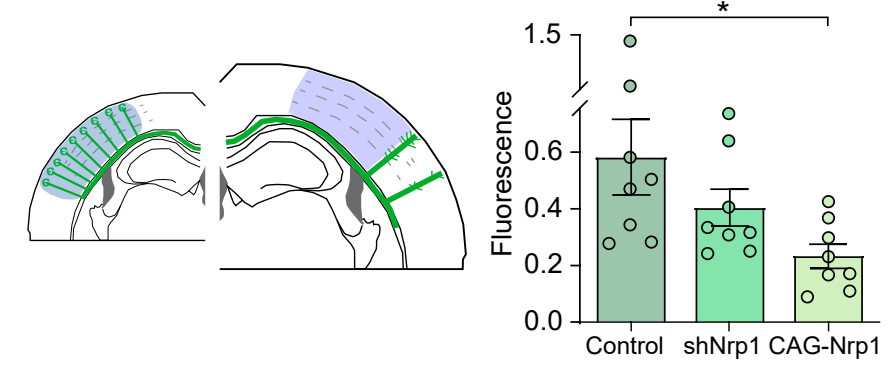

Figure 3 - figure supplement 1 . Analysis of contralateral innervation of SS cortex at P16 upon Nrp1 modifications. A-B) Quantification of contralateral $\mathrm{GFP}^{+}$axons. Mean \pm SEM ( $\mathrm{n} \geq 4$ brains, 2 sections per brain in all conditions). A) $\mathrm{S} 2$ innervation relative to $\mathrm{S} 1$ innervation (One-way ANOVA: $P$-value $=0.6260$ (n.s.)). B) $\mathrm{S} 1$ area (One-way ANOVA: $P$-value $=0.0385$. Posthoc with Tukey's test: ${ }^{*} p$-value controlCAG-Nrpl $=0.0300)$. 
bioRxiv preprint doi: https://doi.org/10.1101/2021.05.12.443798; this version posted May 14, 2021. The copyright holder for this preprint (which was not certified by peer review) is the author/funder, who has granted bioRxiv a license to display the preprint in perpetuity. It is made available under aCC-BY-NC-ND 4.0 International license.

Figure 5 - figure supplement 1
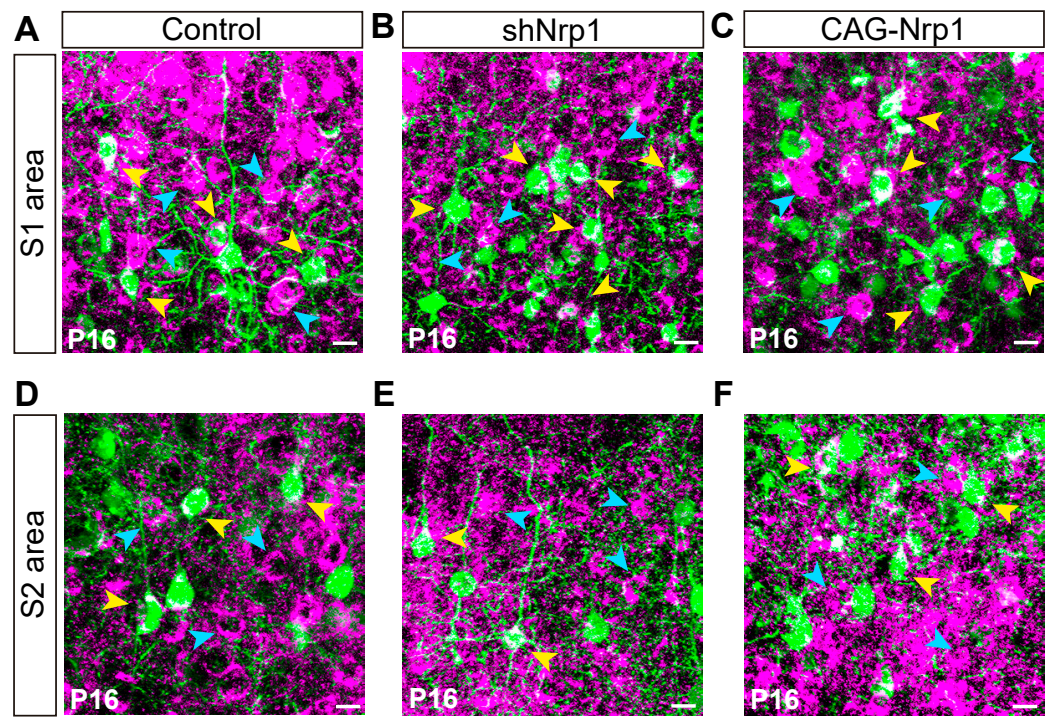

E
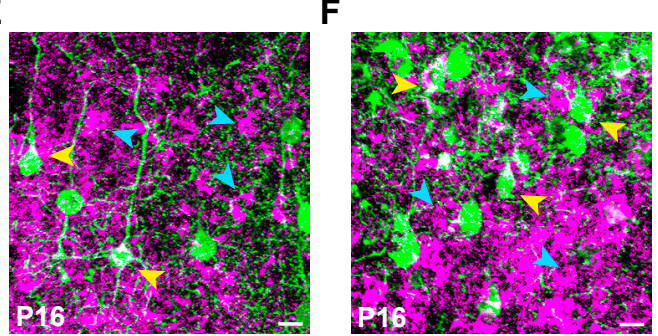

G

H

CPNs in S2
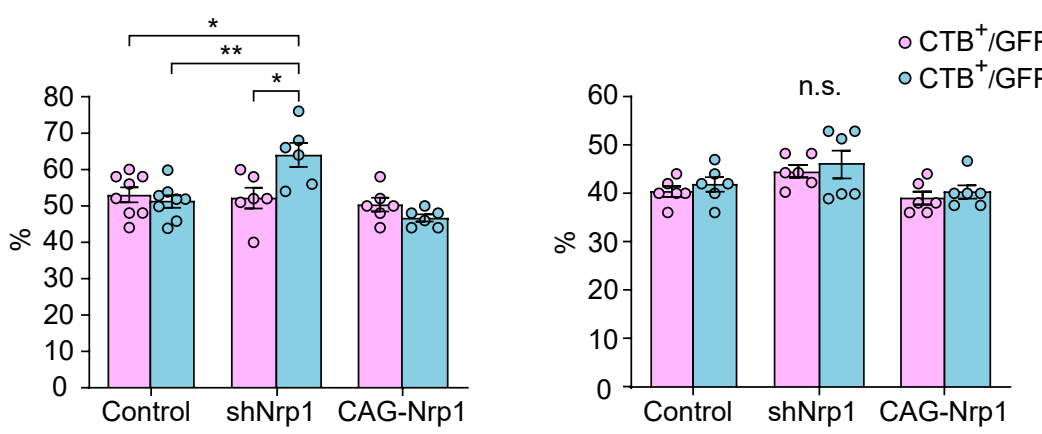

Figure 5 - figure supplement 1. CPNs proportions of non-electroporated and electroporated neurons at P16. A-F) Images of $\mathrm{L} 2 / 3$ populations $\left(\mathrm{CTB}^{+}\right.$, blue arrowheads; $\mathrm{GFP}^{+} \mathrm{CTB}^{+}$, yellow arrowheads). Scale bar $=10 \mu \mathrm{m}$. A-C) S1L2/3 neurons. D-F) S2L2/3 neurons. G-H) Proportion of $\mathrm{CTB}^{+} / \mathrm{GFP}^{-}$neurons, and $\mathrm{GFP}^{+} \mathrm{CTB}^{+} / \mathrm{GFP}^{+}$ in $\mathrm{S} 1$ area and S2 area. Mean \pm SEM ( $\mathrm{n} \geq 3$ brains, 2 sections per brain in all conditions). G) S1 CPNs (Two-way ANOVA: $P$-value Experimental condition $=0.001 ; P$-value Population $=0.242$. Posthoc with Tukey's test: $* p$-value shNpl GFP--shNrpl GFP+ $=0.0127 ; * *$-value Control GFP+ - shNipl GFP $=0.0033 ; * p$-value Control GFP - shNrpl GFP+ $=0.0135)$. H) S2 CPNs (Two-way ANOVA: $P$-value Experimental condition $=0.072$ (n.s.); $P$-value Population $=0.2842$ ). 
bioRxiv preprint doi: https://doi.org/10.1101/2021.05.12.443798; this version posted May 14, 2021. The copyright holder for this preprint (which was not certified by peer review) is the author/funder, who has granted bioRxiv a license to display the preprint in perpetuity. It is made available under aCC-BY-NC-ND 4.0 International license.

Figure 5 - figure supplement 2
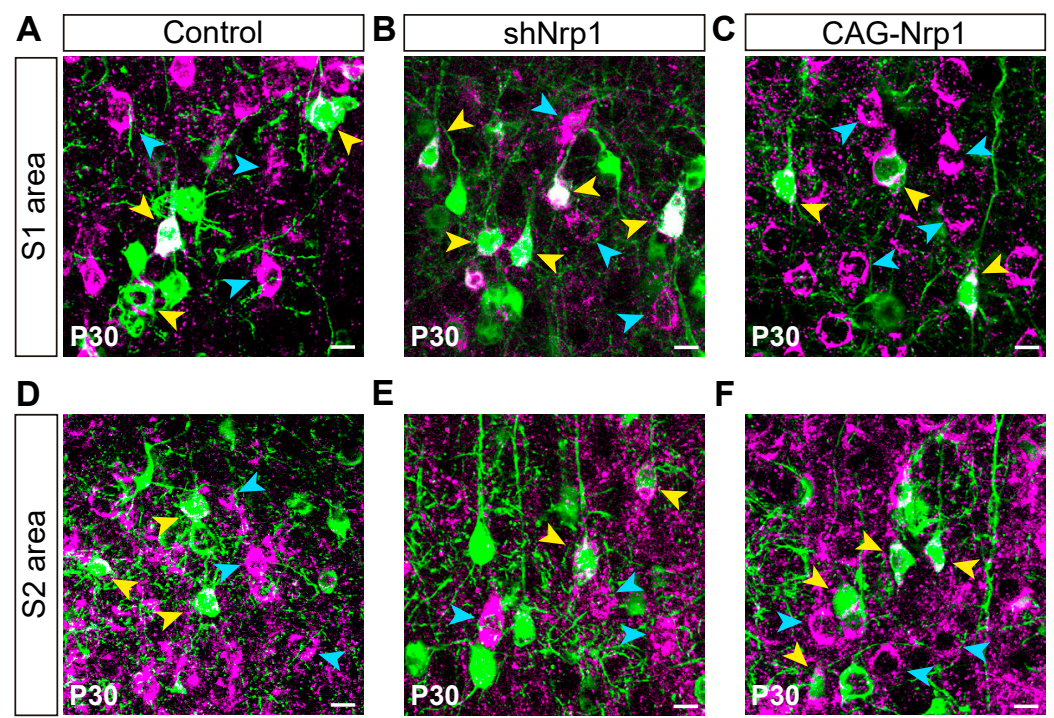

\section{E}

$\mathbf{F}$

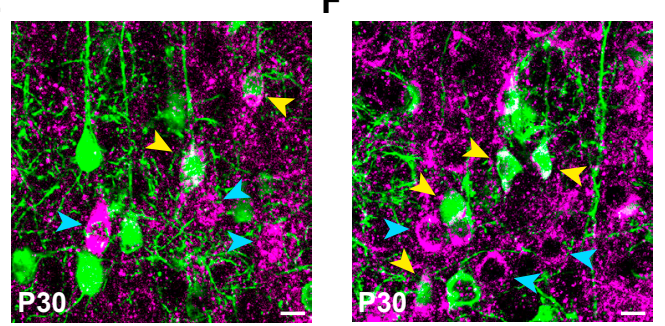

G

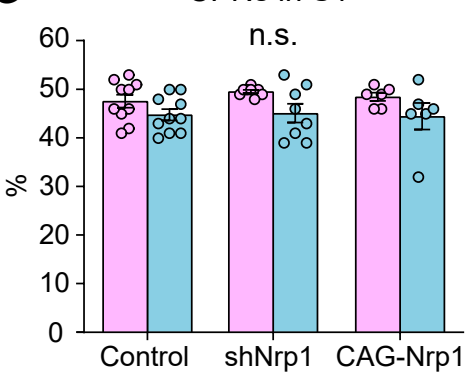

H

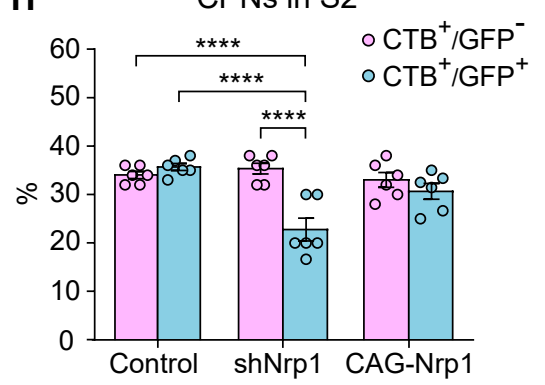

Figure 5 - figure supplement 2. CPNs proportions of non-electroporated and electroporated neurons at P30. A-F) Images of $\mathrm{L} 2 / 3$ populations $\left(\mathrm{CTB}^{+}\right.$, blue arrowheads; $\mathrm{GFP}^{+} \mathrm{CTB}^{+}$, yellow arrowheads). Scale bar $=10 \mu \mathrm{m}$. A-C) $\mathrm{S} 1 \mathrm{~L} 2 / 3$ neurons. D-F) S2L2/3 neurons. G-H) Proportion of $\mathrm{CTB}^{+} / \mathrm{GFP}^{-}$neurons, and $\mathrm{GFP}^{+} \mathrm{CT}-$ $\mathrm{B}^{+} / \mathrm{GFP}^{+}$in $\mathrm{S} 1$ area and $\mathrm{S} 2$ area. Mean $\pm \mathrm{SEM}(\mathrm{n} \geq 3$ brains, 2 sections per brain in all conditions). G) S1 CPNs (Two-way ANOVA: $P$-value Experimental condition $=0.6998$ (n.s.); $P$-value Population $=0.0041) . \mathrm{H}) \mathrm{S} 2 \mathrm{CPNs}$ (Two-way ANOVA: $P$-value Experimental condition $=$ $0.0018 ; P$-value Population $=0.0008$. Posthoc with Tukey's test: $* * * * *$-value shNrpl CTB+GFP-shNrpl $\mathrm{CTB}+\mathrm{GFP}+<0.0001 ; * * * * p$-value Control $\mathrm{CTB}+\mathrm{GFP}+-\operatorname{shNrp1} \mathrm{CTB}+\mathrm{GFP}+<0.0001 ; * * * * p$-value Control $\mathrm{CTB}+\mathrm{GFP}--$ shNrpl $\mathrm{CTB}+\mathrm{GFP}+<0.0001)$. 